\title{
A performance measurement system for industry 4.0 enabled smart manufacturing system in SMMEs- A review and empirical investigation.
}

\author{
Sachin S.Kamblea Angappa Gunasekaran' Abhijeet Ghadgec ${ }^{\mathrm{c}}$ Rakesh Raut $^{\mathrm{d}}$ \\ a EDHEC Business School, Roubaix, 59057, France \\ ${ }^{\mathrm{b}}$ School of Business and Public Administration, California State University, Bakersfield 9001 Stockdale Highway, 20BDC/140, Bakersfield, \\ CA, 93311-1022, USA \\ ${ }^{\mathrm{c} C e n t r e}$ for Logistics and Supply Chain Management, Cranfield School of Management, Cranfield University, UK \\ ${ }^{\mathrm{d} N a t i o n a l}$ Institute of Industrial Engineering (NITIE), Mumbai, 400087, India
}

\begin{abstract}
:
The smart manufacturing systems (SMS) offer several advantages compared to the traditional manufacturing systems and are increasingly being adopted by manufacturing organizations as a strategy to improve their performance. Developing an SMS is expensive and complicated, integrating together various technologies such as automation, data exchanges, cyber-physical systems (CPS), artificial intelligence, internet of things (IoT), and semi-autonomous industrial systems. The Small, Medium and Micro Enterprises (SMMEs) have limited resources and therefore, would like to see the benefits from investments before allowing adopting SMS. This study uses a combination of exploratory and empirical research design to identify and validate the performance measures relevant to the evaluation of SMS investments in auto-component manufacturing SMMEs based in India. The study found that an Industry 4.0 enabled SMS offer more competitive benefits compared to a traditional manufacturing system. The planned investments in SMS can be evaluated on ten performance dimensions namely, cost, quality, flexibility, time, integration, optimized productivity, real-time diagnosis \& prognosis, computing, social and ecological sustainability. Proposed novel Smart Manufacturing Performance Measurement System (SMPMS) framework is expected to guide the practitioners in SMMEs to evaluate their SMS investments.
\end{abstract}

Keywords: Smart manufacturing system, Industry 4.0, Performance measurement, SMMEs, Automotive industry, Digital transformation. 


\section{Introduction}

Small, Medium and Micro enterprises (SMMEs) have helped to accelerate economic development in Asia (Ndubisi et al., 2020). Along with the large enterprises, they are also adopting Industry 4.0 technologies for improved performance. Industry 4.0 is the latest trend in the manufacturing technologies that transform the existing manufacturing systems to Smart Manufacturing Systems (SMS) through the support of automation, data exchanges, cyberphysical systems (CPS), cloud computing, robotics, big data, artificial intelligence, internet of things (IoT) and semi-autonomous industrial techniques (Kamble et al., 2018a). The manufacturing goals achieved by the Industry 4.0 lies in the intersection of people, technologies and innovation. With tremendous development in the field of manufacturing and data analytics technologies (Zhang et al., 2019; Qu et al., 2019). Much of these developments are focused on digital manufacturing systems and artificial intelligence techniques, transforming the systems to become smart and intelligent (Edgar and Pistikopoulos, 2018). The SMS generates a considerable amount of data; however, the use and volume of the data collected vary across the industries, their scale, and operations (Kusiak, 2017).

Zheng et al. (2018) identified significant applications of SMS in design, machining, monitoring, control and scheduling. The use of computer-aided design and manufacturing software, immersive and non-invasive hybrid prototyping technologies- such as augmented reality (AR) and visual reality (VR) and the ability to interact within the cyber-physical systems in a manufacturing environment help companies to establish smart design architectures (Kamble et al., 2018a). The SMS eliminates the need for post-process quality inspections and enables a self-optimization control system with the use of sensors, IoT, machine learning and cloud computing technologies (Stoyanov et al., 2019). The deployment of IoT provides SMS the capability for real-time monitoring and control, resulting in the improved quality of operations, reduction in product and machine failures and development of optimal schedules (He et al., 2019; Liang et al., 2019).

Several organizations are implementing Industry 4.0 technologies to address the challenges of increasing manufacturing complexity (Oh and Jeong, 2019). The real-time based technologies transform the reactive operational approach of the manufacturing facilities into a proactive approach (Davis et al., 2012). Jung et al. (2015) report that for the SMS to be efficient, they need to be able to respond to the information quickly and effectively, and in the process may disrupt the ongoing operations.

The SMS need to be agile and able to meet the rigorous performance requirements to become successful in achieving their implementation goals. No doubt that the implementation 
of SMS in the SMMEs will increase the production activities, but would also result in complex operational issues, with concerns for the economic, environment, social and resource sustainability (Ndubisi et al., 2020). The literature suggest that even though Industry 4.0 has demonstrated significant potential in value creation and digital supply chain transformation, the scholarly research emphasizing the significance of Industry 4.0 on the manufacturing supply chain is still embryonic and the sustainability issues has received little attention (Buyukozkan and Goçer, 2018).

The performance measurement of SMS is one of the most critical issues from the managerial viewpoint. The development of an SMS requires support from different supply chain partners in terms of collaboration, human resources, coordination, organizational and technological capabilities (Kamble et al., 2020c). Further, with the implementation of SMS, the SMMEs will expect improvements in the areas of productivity, integration, transparency, flexibility and profitability (Ndubisi, 2020). To ensure that the SMS will pursue those aspects, a performance measurement system plays a vital role in systematic management (Kamble and Gunasekaran, 2020). However, the research in SMS performance measurement is largely scarce. In the past, there have been numerous studies in the literature to identify and collate performance measures to evaluate supply chain performance. These studies classified the performance measures as; 'qualitative' or 'quantitative' (Beamon 1999; Shepherd and Günter 2006); 'cost' or 'non-cost' (Gunasekaran et al., 2001), 'quality,' 'cost,' 'delivery,' 'flexibility,' 'strategic,' 'operational' or 'tactical' (Shepherd and Günter, 2006). Few studies classified the measures based on 'resource utilization,' 'visibility,' 'trust,' and 'innovativeness' (Chan 2003) and 'supply chain operational reference' framework (Lockamy and McCormack 2004).

Continuous review of the performance measures is required to be undertaken, as they keep changing with the developments in the competitive environment; hence, making the design, development and implementation of the performance measurement system a continuous process and not a one-time activity (Beamon 1999; Kamble and Gunasekaran, 2020). In traditional manufacturing systems, the performance measurement systems are based on historical information that is isolated and static (Lapide, 2010). The SMS are highly proactive with the capability to collect information that is fast-changing and highly volatile. Hence, the decision-makers will be interested in anticipating future performance instead of reacting to problems that occurred in the past (Stefanovic, 2015). Researchers have highlighted the need for studies on performance measurement in the changing context of Industry 4.0 and smart manufacturing systems (Frederico et al. 2019; Frederico et al. 2020; Kamble et al., 2018a; Ghadge et al., 2020). 
Few research studies have proposed a performance measurement framework for Industry 4.0 based manufacturing systems (Shin et al., 2018; Miragliotta et al., 2018; Bauters et al., 2018; Ante et al., 2018; Emmer et al., 2018). However, the proposed performance measures in these studies are limited to the evaluation of a specific performance dimension; such as data quality, productivity or product quality. Moreover, these studies used literature reviews or case study approaches and lack in providing empirical validity for the measures. There is a need to conduct empirical studies seeking practitioners' views on the adequacy and applicability of performance dimensions in the Industry 4.0 context (Frederico et al., 2020). Thus, a significant knowledge gap is evident in developing a holistic performance measurement system for SMS within the context of Industry 4.0. Accordingly, this paper aims to address the research gap in the literature by identifying the performance measures using a combination of literature review and empirical validation. The empirical validation in this study is performed on selected Industry practitioners from SMMEs in India. This is relevant considering the substantial investment costs in implementing Industry 4.0 based SMS and the limited financing options available to the SMMEs (Gawankar et al., 2020; Kiel et al., 2017a; 2017b). The SMMEs would prefer to apply SMS in gradual steps and see the results before proceeding further with holistic implementation. The contribution of SMMEs towards a country's economic and social development is high (Ndubisi et al., 2020), and SMS implementation will provide a considerable stimulus for the nation's growth. The performance measures identified in this study are expected to support and foster the speed of Industry 4.0 enabled SMS implementation in SMMEs. More specifically, the following research questions (RQ) were addressed in this study.

RQ1: What performance measures can be used to evaluate the performance of SMS in SMMEs?

RQ2: How can these measures be used to evaluate the SMS performance in SMMEs?

The study uses a three-phase research methodology to seek answers to the above research questions. Phase-I used a literature review to identify the performance measures in the context of SMS. In phase-II, a preliminary survey was conducted in 142 auto-component manufacturing SMMEs to explore the possible underlying factor structure of the performance measures. The final study was conducted in Phase-III on 254 practitioners from 180 autocomponent manufacturing SMMEs to validate the factor structure of performance measures identified in Phase-II. A Smart Manufacturing Performance Measurement System (SMPMS) framework is developed based on the findings of the study, which will guide the practitioners in the SMMEs on how to evaluate the SMS performance. 
The remaining of the paper is structured as follows; section two presents the conceptual background of the study and relevant literature review on performance measures in SMS. The third section discusses the three-phase research methodology adopted in this study. The results of the study are presented in the fourth section. The fifth section offers the discussions and implications of the study. The SMPMS framework is discussed in section six. Finally, in the sixth section, conclusions with future research possibilities and limitations are discussed.

\section{The conceptual background of the study}

\subsection{Overview of SMMEs in India}

The estimated market growth driven by SMAC (social, mobile, analytics, and cloud) is expected to be 30\% (US\$1 trillion) by 2020 (NASSCOM, 2018). The SMMEs will play a leading role in the adoption of SMAC to bring operational efficiency and transform the customer experience. The SMMEs are continually looking forward to enhancing their competitiveness by adopting Industry 4.0 technologies (Mashelkar, 2018). There exists a significant economic potential for the SMMEs to transform into smart factories, integrating information communication technologies (ICT) and CPS with manufacturing, logistics, and supply chain planning (Lee and Lapira, 2013; Ndubisi et al., 2020). In India, the SMMEs are the major contributors to industrial development, with a share of $40 \%$ in industrial production and $35 \%$ of the total manufactured exports (Mathur, 2019). The literature identifies pressure on SMMEs to achieve continuous quality improvements, extensive manual interventions in processes, interrupted data flow and lack of skilled workforce as the critical barriers for implementing Industry 4.0 technologies (Kamble et al., 2018b). The Government of India is supporting the SMMEs to develop SMS through various initiatives such as 'Make in India,' 'Technological up-gradation,' and 'Establishment of facilitation centers.' The government is in the process of developing a regulatory framework that is more conducive for enabling an Industry 4.0 ecosystem in the country (KPMG-AIMA, 2018).

In India, the Micro, Small and Medium Enterprises (MSMEs) are classified in two classes as per the provision of the MSMEs Development Act, 2006 of the Government of India. The first class pertains to the "enterprises that are engaged in the manufacturing or production of goods or employing plant and machinery in the process of value addition to the final product having a distinct name or character or use" (Ministry of MSME, 2019). The second class includes the "enterprises engaged in providing or rendering of services and are defined in terms of investment in equipment" (Ministry of MSME, 2019). The limit of investments that are used to categorize these enterprises into micro, small and medium categories is presented in Table 1. 
Table 1: Investment limit in the plant, machinery, and equipment for MSMEs (Source:

Ministry of MSME, India)

\begin{tabular}{|l|l|l|}
\hline \multirow{2}{*}{ Size } & \multicolumn{2}{|c|}{ Investment Limit (INR) } \\
\cline { 2 - 3 } & Manufacturing Enterprise & Service Enterprise \\
\hline Micro & Less than 2.5 million & Less than 1 million \\
\hline Small & 2.5 million -50 million & 1 million -20 million \\
\hline Medium & 50 million -100 million & 20 million -50 million \\
\hline
\end{tabular}

In spite of several benefits offered by the Industry 4.0 technologies, very few SMMEs can afford the smart manufacturing solutions. The ICT based technology adoption in the Indian SMMEs can be described in four stages. Stage 1 includes organizations that have a basic level of technology for communication and data processing. In stage 2 , the organizations use standalone software to execute functional tasks without any cross-functional interactions or linkages. For e.g., the use of accounting software to generate profit and loss statements. In the third stage, the organizations use enterprise resource planning applications to automate and integrate their core business functions. The fourth stage represents the highest level of technological maturity with the SMMEs using digital networks and real-time decision-making systems. The organizations in this stage are willing to invest in innovative IT solutions to enhance their value chain integration (Ndubisi, 2008; Ndubisi et al., 2020).

The present status of SMMEs in India reveals that medium-sector enterprises have more matured technology than micro and small-scale enterprises (Mathur, 2019). The huge upfront investment cost in technology is identified as a significant barrier to SMS adoption (Kamble et al., 2018b). Understandably, the SMMEs prefers to invest in such systems using a step-by-step approach as these SMMEs are constrained with the budget and, therefore, would see the benefits from the investments before allowing their management, customers, and employees to adopt the technology (Ndubisi, 2008). Thus, the focus of this study is to provide a validated set of performance measures and a performance measurement system for the SMMEs to manage successful SMS implementation.

\subsection{Performance measures in traditional manufacturing systems}

Performance measurement is defined as "the process of quantifying the efficiency and effectiveness of action" (Neely et al., 1995). The performance measures should support improving organizational performance and create a supportive work environment (Bititci et al., 2005). Majority of the previous studies have developed performance measures and metrics for overall supply chain management (Gunasekaran et al., 2001; Bititci et al. 2005; Shepherd and Günter 
2006). Although these studies offered some performance measures for manufacturing systems, the primary focus of these studies was supply chain performance measures.

The measurement of manufacturing performance is a challenging task because of the diverse and multi-dimensional nature of manufacturing. Hon (2005) conducted a survey to identify widely used performance measures in the aerospace industry. The measures were classified into five dimensions, namely, cost, quality, flexibility, time and productivity. The study identified that most of the organizations used overall lead-time, on-time delivery, operating costs, inventory level, and scrap rate as relevant measures along with quality. Diego and Rivera (2007) combined various metrics consistent with the different stages and elements of lean manufacturing. They classified 21 performance metrics in six categories that included elimination of waste, continuous improvement, continuous flow, pull driven system, multifunctional teams, and information systems. The high investment and operating costs in developing automated manufacturing systems required many organizations to consider Overall Equipment Effectiveness (OEE) as one of the critical metrics in performance measurement (Mathur et al., 2011). The maintenance performance measures, such as condition-based maintenance and reliability-centered maintenance were found to create value for the organizations (Kumar et al., 2013). While classifying 73 measures into twelve performance dimensions, Gosselin (2005) found that manufacturing organizations prefer financial measures over the non-financial measures (Gosselin, 2005). Kamble and Gunasekaran (2020) conducted a study in the context of the big data-driven supply chain, identifying new measures such as predictive quality, real-time fault-finding and predictive machine failure to evaluate the manufacturing systems. The study highlighted that the predictive analytics capability of datadriven manufacturing supply chains provides organizations the ability to proactively plan for, what may occur in the future instead of analysing the reasons for what has happened in the past.

The measurement systems should be dynamic and align manufacturing strategy to drive competitive and innovative performance (Hon, 2005). The above discussions suggest that the performance measures have evolved with the changing environment, and the recent advancements in the Industry 4.0 technologies are offering new possibilities to monitor and control performance in real-time. This justifies the need to review and validate relevant performance measures for the SMS. 


\subsection{Performance Measures for Smart Manufacturing Systems}

\subsubsection{Cost measures}

The literature reveals that the reduction in manufacturing costs is one of the critical focus of SMS. The performance measures used to demonstrate the benefits of SMS are general cost measures that are used in the traditional manufacturing systems and included profit (Pistolesi et al., 2019; Roy et al., 2015), work-in-process cost (Fan et al., 2019), energy cost (Gadaleta et al. 2019; Edgar and Pistikopoulos, 2018), maintenance cost (Vogl et al., 2019), waste treatment cost (Santos et al., 2019) and inventory cost (Chen and Kuo, 2019; Castellano et al., 2019). Most of the above studies compared the SMS performance with the traditional manufacturing systems on the cost measures and claimed that an SMS performs far better than a conventional manufacturing system offering higher cost-saving benefits (Alqahtani et al., 2019; Gadaleta et al., 2019).

\subsubsection{Quality measures}

The use of information and communication technologies such as IoT, machine learning and predictive analytics enable SMS to perform real-time monitoring and proactive control of the products, processes and equipment. The predictive capability of SMS makes them superior to the traditional manufacturing systems, enabling the SMS to detect product failure in real-time (He et al., 2019; Liang et al., 2019), predict the remaining useful life of the machine (Kumar et al., 2019; He et al., 2019), early process fault detection (Carvajal Soto et al., 2019) and process visualizations (Qian et al., 2019). Further, the SMS performs efficiently on the measures of warranty claims by the customers (Alqhatani et al., 2019), reduced scrap (Chauhan et al., 2019; Rajput and Singh, 2019), the defective product (Kucukogulo et al., 2018; Kang et al., 2018) and inspection errors (Kang et al., 2018; Uva et al., 2018). The SMS promotes supply chain integration by developing the superior quality of supplier relationships, collaborative partnerships (Longo et al., 2019; Wang et al., 2019b) and improved customer satisfaction (Petrillo et al., 2017).

\subsubsection{Computing measures}

The Industry 4.0 technologies and architectures are required to connect and extend the physical factory operations with the cyber world needing greater information consistency, data reliability, information privacy and security (O’Donovan et al., 2019). Zhao et al. (2019) suggest the use of advanced ICT and IoT for effective implementation of SMS for improved product traceability and information security. Data storage capacity, lack of human skills, information privacy and high latency are significant challenges that affect the performance of an SMS (Li et al., 2019). The highly secured network is identified as a critical requirement for managing 
the human-robot collaboration in enhancing SMS performance (Khalid et al., 2018). Hence, for the efficient performance of SMS, it is critical to have a reliable data management system that includes data collection, data transfer, data storage and data analytical capabilities.

\subsubsection{Human measures}

The impact of technological advancements on the human resources have also received attention in the literature (Pinzone et al., 2019; Eimontaile et al., 2019; Kamble et al., 2020c; Tortorella et al., 2020). Pinzone et al. (2019) suggest that SMS supports building a robust social environment enabling improved employee health, learning and operative performance. The technologies such as virtual and augmented reality accelerate employee learning, thus reducing the work pressure and increase in morale (Uva et al., 2018; Kamble et al., 2018; Blanco-Novoa et al., 2018). The other human factors on which the SMS performance could be evaluated are reduced human efforts \& anxiety, improved working conditions and non-invasive interventions (Kamble et al., 2018; Roldan et al., 2019; Eimontaile et al., 2019). The above studies suggest that the SMS support in developing a human-friendly environment by not only offering improved physical comfort, but also relieving the psychological stress on the employees.

\subsubsection{Productivity measures}

SMS encourages the use of advanced optimization and simulation techniques because of the availability of a considerable amount of data that is generated in real-time at different locations in the manufacturing supply chains. The literature reveals that the prescriptive analytical techniques have been deployed extensively in SMS to optimize the machining processes (Liang et al., 2019; Zhao et al., 2017; Biondi et al., 2018), plant and warehouse layouts (Banyai et al., 2019; Peruzzini et al., 2019), use of materials (Chauhan et al., 2019; Meng et al., 2018), workstation design (Pistolesi et al., 2018) and workflows (Tufano et al., 2018). Compared to the conventional manufacturing systems, the productivity measures in the SMS relies more on the use of optimization and simulation techniques to make the operations productive.

\subsubsection{Flexibility measures}

In the traditional manufacturing systems, flexibility is evaluated on various performance measures that include the system flexibility in terms of product mix, delivery, process, machine, and volume. However, SMS extends these flexibility performance measures to include the ability to execute real-time job scheduling (Saif et al., 2019; Fan et al., 2019; Framinan et al., 2019) real-time design and engineering changes (Davis et al., 2012), real-time monitoring of customer orders (Qu et al., 2019; Petrillo et al., 2019), and real-time supply status of products (Longo et al., 2019; Oh and Jeong 2018). Hence, the SMS performs efficiently on providing 
real-time flexibility to the manufacturing organizations, enabling them to make real-time decisions on various aspects such as interaction with the suppliers, internal customers, and the end customers.

The list of performance measures reviewed from the literature on SMS is summarised in Table 2. The dimensions used for classification of these measures were based on existing classification schemes used in the literature and the discussion with the industry practitioners from the auto-component manufacturing SMMEs.

\subsection{Performance measurement of smart manufacturing systems}

The research on performance measurement systems for Industry 4.0 is scarce, with limited research studies attempting to develop evaluation systems for smart manufacturing projects in Industry 4.0 (Ante et al. 2018). Ante et al. (2018) proposed a performance management system for lean production system in the automotive industry in the Industry 4.0 context. Emmer et al. (2019) proposed a comprehensive measurement data management (MDM) system focused on the technological requirements of Industry 4.0 for complex process chains. The proposed framework integrated the flow of information within quality assurance using neutral data formats and achieved comprehensive interoperability of the individual system components. Miragliotta et al. (2019) identified the need to measure data productivity in the context of Industry 4.0. Inspired by the traditional OEE framework, the data measurement model measures data productivity on the performance dimensions of data availability, quality and decision-making process. The performance measurement model developed by Shin et al. (2018) evaluated the quality aspects of an organization in the context of Industry 4.0. The framework used the existing performance measures regarding the costs of quality items and developed a virtual tool to assess weaknesses in the current manufacturing systems. Frederico et al. (2019) developed a performance measurement system for Industry 4.0 based supply chains using the Balanced Scorecard (BSC) framework.

Although above discussed studies in the literature have attempted to establish measurement systems in the Industry 4.0 context, the measures considered by them are not comprehensive and directed towards a specific performance dimension. Further, these studies have used conceptual frameworks or case studies within the organization to develop the measurement system, lacking empirical validation of the identified measures. 

and empirical investigation", International Journal of Production Economics, 229, 107853.

Table 2: Literature Review on Performance Measures in Smart Manufacturing Systems

\begin{tabular}{|c|c|c|}
\hline Dimensions & Measures & Key Sources \\
\hline \multirow{14}{*}{ Cost } & Cost per unit produced (C2) & Stoyanov et al., 2019; Edgar and Pistikopoulos, 2018; Gosselin, 2005 \\
\hline & Energy cost (C3) & Gadaleta et al., 2019; Santos et al., 2019; Edgar and Pistikopoulos, 2018; Meng et al., 2018 \\
\hline & Process maintenance cost (C4) & Vogl et al., 2019; Kumar et al., 2019; Algahtani et al., 2019 \\
\hline & Profit (C6) & Pistolesi et al., 2018; Roy et al., 2015; Kamble et al., 2019 \\
\hline & $\mathrm{R} \& \mathrm{D} \operatorname{cost}(\mathrm{C} 7)$ & Wang and Nee (2009) \\
\hline & New product development cost (C8) & Roy et al., 2015 \\
\hline & Raw material purchasing cost (C9) & Kamble et al., 2019 \\
\hline & WIP Cost (C12) & Fan et al., 2019 \\
\hline & Energy consumption prediction (C13) & Chen et al., 2019; Raileanu et al., 2017 \\
\hline & Return on Asset (C14) & Roy et al., 2015; Kusiak (2019) \\
\hline & Operating cost (C15) & Castellano et al., 2019; Zhang et al., 2019; Mathur et al., 2011; Edgar et al., 2011; Renna, 2019 \\
\hline & Manufacturing cost (C16) & Giusti et al, 2018; Bányai et al., 2019; Zhang et al., 2019 \\
\hline & Setup cost (C17) & Renna, 2019; Zhang et al., 2018 \\
\hline & Inventory cost (C18) & Chen and Kuo, 2019; Fan et al., 2019; Castellano et al., 2019 \\
\hline \multirow{11}{*}{ Quality } & Defective product $(\mathrm{Q} 4)$ & Kucukogulo et al., 2018; Kang et al., 2018 \\
\hline & Reduced inspection error (Q5) & Renna, 2019 \\
\hline & Mean time between failures (Q6) & Kang et al., 2018; Uva et al., 2018 \\
\hline & Real-time detection of product failure (Q7) & He et al., 2019; Liang et al., 2019; Carvajal Soto et al., 2019; Fantini et al., 2018 \\
\hline & $\begin{array}{l}\text { Process visualization and control }(\mathrm{Q} 8) \\
\end{array}$ & Qian et al., 2019; Edgar and Pistikopoulos, 2018 \\
\hline & Machine life prediction(Q9) & He et al., 2019; Kumar et al., 2019; Zhang et al., 2018 \\
\hline & $\begin{array}{l}\text { Redundancy (backup stations) (Q10) } \\
\end{array}$ & Muller et al., 2018 \\
\hline & Early fault detection (Q11) & He et al., 2019; Liang et al., 2019; Carvajal Soto et al., 2019; Lu et al., 2019; Bagheri et al., 2018 \\
\hline & Machine state condition monitoring (Q12) & Liang et al., 2019; Fu et al., 2019; Wang et al., 2019a; Alghatani et al., 2019; Mourtzis et al., 2018 \\
\hline & Reduced inspection quantities(Q13) & Kang et al., 2018 \\
\hline & Product qualification testing time(Q14) & Stoyanov et al., 2019; \\
\hline
\end{tabular}


Kamble, S. S., Gunasekaran, A., Ghadge, A. and Raut, R. (2020), “A performance measurement system for industry 4.0 enabled smart manufacturing system in SMMEs- A review and empirical investigation", International Journal of Production Economics, 229, 107853

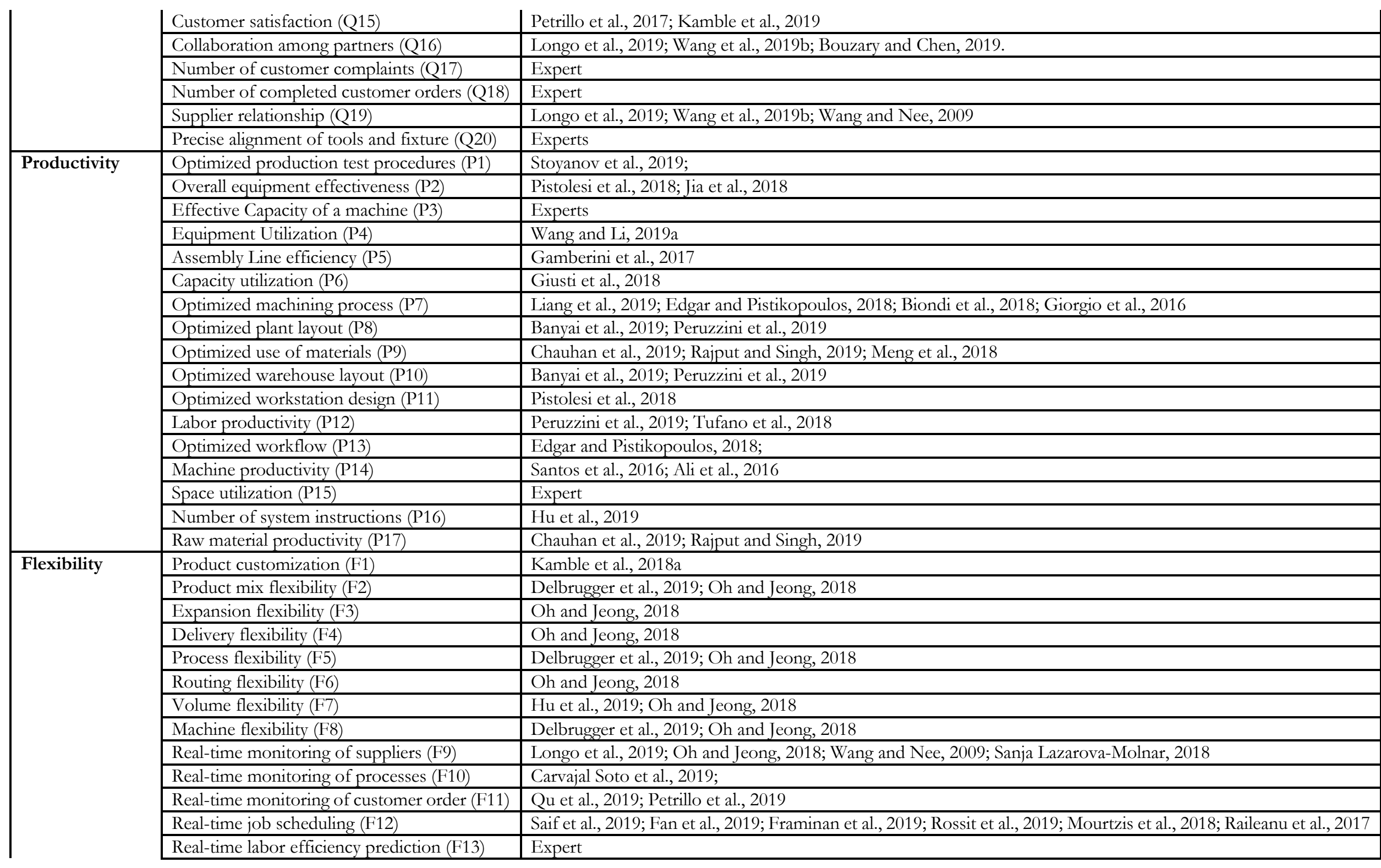



and empirical investigation”, International Journal of Production Economics, 229, 107853.

\begin{tabular}{|c|c|c|}
\hline \multirow[t]{5}{*}{ 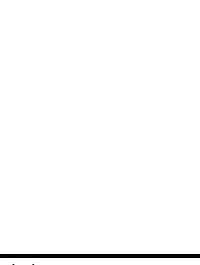 } & $\begin{array}{l}\text { Real-time design and engineering changes } \\
\text { (F14) }\end{array}$ & Davis et al., 2012 \\
\hline & Dynamic order allocation (F15) & Expert \\
\hline & Frequency of re-scheduling (F16) & Expert \\
\hline & Dynamic workstation assignments (F17) & Tufano et al., 2018 \\
\hline & Dynamic line balancing (F18) & Experts \\
\hline \multirow{11}{*}{ Time } & Production time $(\mathrm{T} 1)$ & Sari and Yulia, 2019; Sanja Lazarova-Molnar, 2018 \\
\hline & Mean Flow time (T2) & Rossit et al., 2019 \\
\hline & Processing time (T3) & Fu et al., 2019 \\
\hline & On-time delivery (T4) & Expert \\
\hline & Makespan (T5) & Wei et al., 2018 \\
\hline & Job flow time (T6) & Rossit et al., 2019 \\
\hline & Throughput time (T7) & Castellano et al., 2019; Muller et al., 2018 \\
\hline & Cycle time (T8) & Experts \\
\hline & Lead time $(\mathrm{T} 9)$ & Giusti et al., 2018; Ali et al., 2016; Mittal and Jain, 2014 \\
\hline & Setup time (T10) & Renna, 2019 \\
\hline & Machine uptime (T11) & Santos et al., 2016 \\
\hline \multirow{10}{*}{$\begin{array}{l}\text { Human } \\
\text { Interaction }\end{array}$} & Reduced human efforts (H1) & Pinzone et al., 2019; Blanco-Novoa et al., 2018; Uva et al., 2018 \\
\hline & Improved employee health (H2) & Kamble et al., 2019 \\
\hline & Improved employee learning $(\mathrm{H} 3)$ & Pinzone et al., 2019; Blanco-Novoa et al., 2018; Uva et al., 2018 \\
\hline & Employee morale (H4) & Kamble et al., 2019; Tortorella et al., 2020; Bordel and Alcarria, 2017 \\
\hline & Reduced work pressure $(\mathrm{H} 5)$ & Kamble et al., 2019; Tortorella et al., 2020 \\
\hline & Improved working conditions (H6) & Kamble et al., 2019; Tortorella et al., 2020 \\
\hline & Reduced incidence of injuries $(\mathrm{H} 7)$ & Kamble et al., 2019 \\
\hline & Reduced labor claims (H8) & Kamble et al., 2019 \\
\hline & Non-invasive interactions (H9) & Roldan et al., 2019c \\
\hline & Reduced employee anxiety (H10) & Eimontaite et al., 2019 \\
\hline \multirow[t]{7}{*}{ Computing } & Computing skills (CC1) & Expert \\
\hline & Data reliability (CC2) & Tao et al., 2019; Li et al., 2019 \\
\hline & Data speed (CC3) & Li at al., 2019; Tao et al., 2019 \\
\hline & Information security and privacy (CC4) & Zhao et al., 2019; O’Donovan et al., 2019); Khalid et al., 2018 \\
\hline & Latency (CC5) & (O’Donovan et al., 2019; Tao et al., 2019 \\
\hline & Data storage (CC6) & Zhao et al., 2019; O’Donovan et al., 2019; Tao et al., 2019 \\
\hline & Analytical skills (CC7) & Zhao et al., 2019; O’Donovan et al., 2019; Wu et al., 2017 \\
\hline
\end{tabular}




\section{Research methodology}

A three-phase research methodology with a combination of exploratory and empirical investigations was adopted to propose a validated set of measures and to evaluate the SMS performance in SMMEs. As shown in Fig.1, phase one of the study was aimed at the development of the measurement items and establish content validity. An extant literature review and interview with the industry practitioners were conducted in this phase (Flynn et al., 1990). Phase two used a preliminary survey to explore possible underlying factor structure of the performance measures identified in phase-I, to finalize the measurement items (Child, 1990; DeVellis, 1991). The factor structure of performance measures determined from Phase-II was validated in Phase III of the study. The investigation resulted in the development of a Smart Manufacturing Performance Measurement System (SMPMS) framework that can be used by the SMMEs practitioners to guide the SMS performance in their organizations.

PHASE I

\begin{tabular}{|c|c|}
\hline $\begin{array}{l}\text { Aim: } \\
\text { Development of the } \\
\text { measurement items } \\
\text { Method: } \\
\text { Literature review of } 98 \\
\text { papers shortlisted from } \\
\text { SCOPUS database and } \\
\text { interviews with twenty- } \\
\text { two industry practitioners. } \\
\text { Analysis: } \\
\text { Qualitative interpretations }\end{array}$ & $\begin{array}{l}\text { Aim: } \\
\text { Exploring the possible } \\
\text { underlying factor structure } \\
\text { of the performance } \\
\text { measures identified in } \\
\text { phase one. } \\
\text { Method } \\
\text { Survey of } 201 \text { industry } \\
\text { practitioners from } 142 \\
\text { MSME in automobile } \\
\text { sector. } \\
\text { Analysis: } \\
\text { Exploratory Factor } \\
\text { Analysis. }\end{array}$ \\
\hline
\end{tabular}

PHASE III

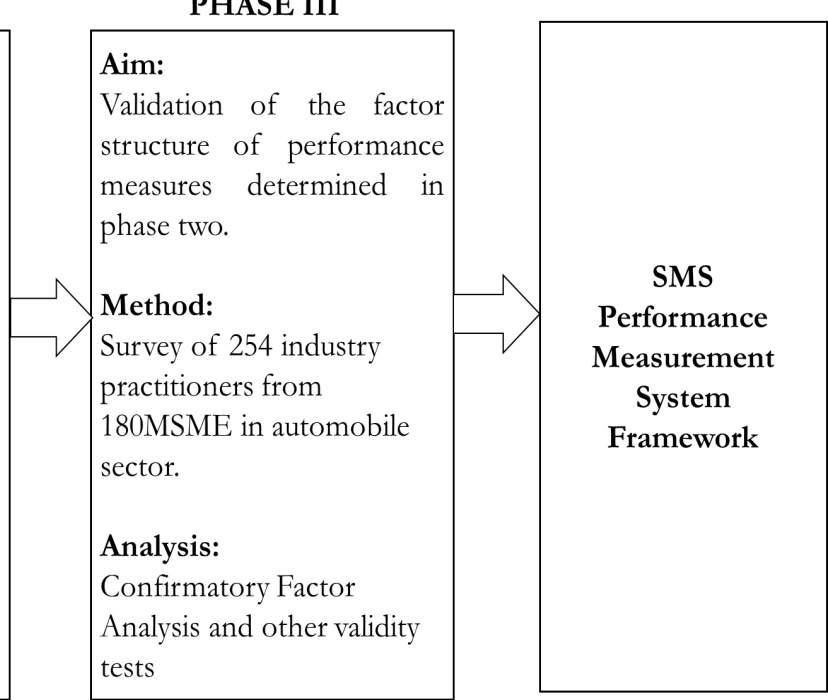

Figure 1: Research methodology

\subsection{Development of measurement instrument (Phase-I)}

\subsubsection{Literature review}

The measurement items for the performance measures were developed using an extant literature review followed by an in-depth unstructured discussion with the practitioners from the manufacturing industry. The discussions with the practitioners helped us to establish the content validity of the identified measures. Similar approaches were used in the previous studies focused on developing measurement items (Parasuraman et al., 1988; Peter et al., 1982). The literature search was performed on the Scopus database using the keywords; "Smart manufacturing" and "Industry 4.0" and "Intelligent Manufacturing" and "Digital manufacturing" in pairwise comparison with "Performance measurement" and "Performance management." The initial search resulted in a total of 1469 papers, which was further reduced 
to 348 articles by limiting the search to papers published in academic journals in the subject categories: business management, operations management, decision sciences, and computer/technology management. Those papers that did not align with the search objectives were not considered for further review. In the end, 98 research papers were selected for the final review. A summary of the chosen articles is presented in Appendix A.

\subsubsection{Content validity of performance measures}

Twenty-two in-depth interviews with industry participants were conducted using open-ended questions to validate the measures identified from the literature subjectively. The practitioners were selected from five Tier-I auto-component manufacturing organizations and had prior knowledge about SMS. Out of these five participating organizations, all of them are using sensor/IoT and cloud computing-based manufacturing systems, two of them have adopted additive manufacturing, and one of them is using virtual reality for training and maintenance activities. The practitioners represented different functional backgrounds that included- manufacturing, maintenance, quality and utilities. The selected practitioners varied in experience levels and held managerial positions like- Vice-president, Chief Manager, Associate Manager, Manager, Director, etc. The practitioners were interviewed on a broad range of SMS performance measures (e.g., what measures they perceived to be necessary for evaluating SMS performance?, Are the performance measures used for traditional manufacturing systems relevant in Industry 4.0 environment?) Few measures were added and some dropped based on the recommendation of the practitioners. The final list of 102 measures was subjectively classified in seven performance dimensions namely, cost, quality, productivity, flexibility, time, human and computing performance as presented in Table 2 .

\subsection{Exploring the underlying factors of performance measures (Phase II)}

In this phase, a preliminary study was conducted to establish the statistical validity of the measurement items identified from Phase I. Exploratory Factor Analysis (EFA) was performed in this phase to determine the underlying performance dimensions and finalize the measurement items for use in the final survey. The data was collected through an online survey of 210 working practitioners from 142 auto-component manufacturers in India. The questionnaire for the second phase of the study included 102 measures. Out of 102 measures, 52 were worded positively and 50 were worded negatively. A fivepoint Likert scale with the extreme values ranging from "Strongly Disagree" (1) to "Strongly Agree" (5) was developed and the respondents were asked about their agreement to what extent the measures could be used for the competitive benefits occurring from SMS investments.

The list of measurement items with the literature source is presented in Table 2. 
The success of Indian SMMEs is driven by auto-component manufacturing companies because of its high technological maturity and massive development prospects. The auto-component industry contributes seven percent of India's Gross Domestic Product (GDP), employing around 19 million people (Arcot, 2017). The auto-component industry is expected to achieve a turnover of USD 113 billion by 2020 and become a significant manufacturing cluster in Asia (Smeventure, 2017). A report by KPMG states that the Indian automotive industry has a high robot density of 58 robots/10000 employees compared to the industry density of just three robots/10000 employees (AIMA-KPMG, 2018). Most of the Indian auto-component manufacturing organizations are in the process of adopting Industry 4.0 based SMS (Kamble et al., 2020c). The potential of auto-component SMMEs and their gradual interest in developing SMS ensured that the sample respondents are aware of the opportunities and challenges in developing SMS and qualified to participate in the survey. The online survey link was sent to 640 respondents, and 210 completed responses were obtained (32.18\% response rate) representing 142 SMMEs. The profile of the selected respondents and SMMEs in the preliminary survey is shown in Table 3.

\subsection{Statistical validation of the factor structure of performance measures}

In this phase, the underlying factors from Phase II were used to conduct the final survey and confirm the factor structure of the performance measures. The measurement items used in this survey were restricted to the underlying performance dimensions identified in Phase-II. A similar profile of respondents who participated in the second phase was approached for the survey. 254 respondents from 180 SMMEs participated in the online survey, which was coordinated by a local survey agency based in India. The design of the study required respondents to answer all the questions before the final submission, eliminating the issue of the incomplete questionnaire and missing values. Similar sample sizes were used in the previous studies that empirically tested the effects of Industry 4.0 technologies on an organisational performance involving around 100 measurement items (Tortorella et al., 2020; Kamble et al., 2020c). The statistical analysis in the Phase I and II was performed after averaging the items with multiple responses from a single organization to obtain a single value for each item (Venkatraman and Grant, 1986). Hence, the effective sampling unit for analysis was the number of participating SMMEs. The profile of the selected respondents and SMMEs in the final survey is shown in Table 3.

The measurement items were tested for convergent and discriminant validity using Composite Scale Reliability (CSR) and Average Variance Extracted (AVE) as per the suggested guidelines (Hair et al., 2014). CFA was used to validate the measurement model and model fit indices such as Chi-square value $\left(\chi^{2}\right)$, degrees of freedom (df), Comparative Fit Index (CFI), Tuckers Lewis Index (TLI) and Root 
Mean Square Error of Approximation (RMSEA) was used as per the guidelines (Hu and Bentler, 1999; Fan et al., 2016).

Table 3: Respondent profile

\begin{tabular}{|l|l|l|l|}
\hline Parameter & Information of respondent & $\begin{array}{l}\text { Preliminary survey } \\
\text { Phase II } \\
\mathbf{( \% )}\end{array}$ & $\begin{array}{l}\text { Final survey } \\
\text { Phase III (CFA) } \\
\mathbf{( \% )}\end{array}$ \\
\hline Gender & & 87.14 & 84.26 \\
& Male & 12.86 & 15.74 \\
\hline Age & Female & 18.09 & 22.09 \\
& Less than 35 years & 42.85 & 46.06 \\
& 35-50 years & 36.19 & 30.31 \\
& 50-60 years & 02.87 & 01.59 \\
\hline Education & Above 60 years & 08.11 & 12.20 \\
& College level (diploma/certificate) & 18.09 & 22.04 \\
\hline Experience in & Undergraduate & 73.80 & 65.76 \\
\hline Manufacturing & Postgraduate and Doctorate & 44.28 & 48.03 \\
domain & Less than 5 years & 33.33 & 37.00 \\
& 5-10 years & 20.00 & 10.23 \\
\hline Work Domain & 10-15 years & 02.39 & 04.74 \\
& Above 15 years & 03.80 & 03.54 \\
& Plant manager & 33.33 & 36.22 \\
& Manufacturing/production & 28.57 & 25.19 \\
& Digitalization and technology & 14.28 & 11.02 \\
& Maintenance & 08.09 & 10.23 \\
& Quality & 07.14 & 06.29 \\
& Plant Utilities & 04.79 & 07.51 \\
\hline Safety and Environment & 08.57 & 12.22 \\
& Carburetor and battery & 07.14 & 14.44 \\
Industry & Brake, lever, and clutches & 22.38 & 24.44 \\
& Interior and exterior press component & 18.88 \\
& Electronic and electrical components & 15.72 & 03.88 \\
& Bearing & 08.09 & 08.33 \\
& Paint/coating/chemical lubricant & 11.43 & 06.15 \\
& Gear/transmission & 09.53 & 11.66 \\
\hline & Casting and casings & 17.14 & 22.22 \\
& Less than 50 & 15.00 & 77.78 \\
\hline & Between 50-250 & 85.00 & \\
\hline
\end{tabular}

\section{Analysis and findings}

\subsection{The underlying factors of performance measures}

The measures derived from the literature review exhibited some overlap across the different performance dimensions and showed a possibility of combining a few of them. This might be due to the exploratory nature of this phase and subjectivity of the experts while validating these measures. An EFA was conducted to overcome the subjectivity involved in identifying the performance and determine the underlying dimensions (Dick and Hagerty, 1971). 


\subsubsection{Resolving the multi-dimensionality issues}

Skewness was used to measure the symmetry of data and Kurtosis to test whether the data are heavytailed or light-tailed relative to a normal distribution. The maximum absolute values for Skewness and Kurtosis were 1.139 (standard error of 0.181 ), and 2.564 (standard error of 0.359 ) were within the permissible limits (Skewness $<2$, Kurtosis $<7$ ) indicating that the data followed a normal distribution (Curran et al., 1996). The possibility of multidimensionality of the performance measures imposed the need to compute Cronbach alpha $(\alpha)$ for all the seven dimensions separately. The $\alpha$ values helped to ascertain the measures that contributed to making up each dimension. The $\alpha$ values ranged from 0.54 to 0.72 . Selected measures from each dimension were dropped to improve the $\alpha$ values within the acceptable range (above 0.70) as per the guidelines suggested for the development of new measures (Hair et al., 2014). An iterative procedure was used to increase the $\alpha$ values, deleting those measures with very low correlations and recomputing the new $\alpha$ values with a revised set of dimensions. The repeated procedure resulted in a set of 84 items, with the $\alpha$ values ranging between 0.76 to 0.94 across the seven dimensions.

The next step was to examine the dimensionality of the 86 performance measures for which EFA with varimax rotation, constrained to a fixed number of factors (seven), was used. The varimax rotation is found to maximize the squared factor loadings variations for each component, providing a linear transformation to components (Dillon and Goldstein, 1984). No clear dimensions emerged from EFA as many of the items (performance measures) loaded simultaneously on several dimensions signifying that the measures overlapped or were dependent on each other. To overcome this problem, the EFA was re-run allowing the intercorrelations among the dimensions by removing the fixed factor constraint. The EFA resulted in evolving a validated set of ten performance dimensions re-assigning many of the measures from the previous dimensions. The inclusion of a performance measure in a dimension was made, if the factor loading score was above 0.5 , ensuring that only the measures that contributed highly to the formation of a given factor were considered. The final list included 59 performance measures. The factor loading details of the 74 performance measures and their assigned dimension are presented in Table 3. As shown in Table 3, five of the seven dimensions developed in the first phase of the study-cost, time, flexibility, quality, and computing performance were retained with a reduced number of measures. Additionally, five new performance dimensions were evolved from the findings of the EFA viz., optimized productivity, integration, real-time diagnosis \& prognosis, social and ecological sustainability. 


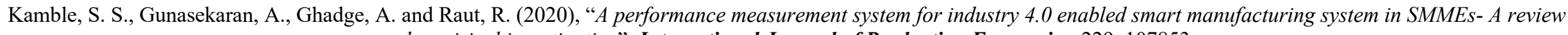
and empirical investigation", International Journal of Production Economics, 229, 107853.

Table 4: Underlying factor structure of performance measures

\begin{tabular}{|c|c|c|c|c|c|c|c|c|c|c|}
\hline \multirow[b]{2}{*}{ Performance Measures } & \multicolumn{10}{|c|}{ Performance Dimensions } \\
\hline & Cost & $\begin{array}{c}\text { Real-time diagnosis } \\
\text { \& Prognosis }\end{array}$ & $\begin{array}{l}\text { Optimized } \\
\text { productivity }\end{array}$ & Quality & Integration & Flexibility & Computing & Time & Social & Ecological \\
\hline Cost per unit produced (C2) & .759 & & & & & & & & & \\
\hline Product maintenance cost (C5) & .805 & & & & & & & & & \\
\hline Profit (C6) & .734 & & & & & & & & & \\
\hline $\mathrm{R} \& \mathrm{D}$ cost $(\mathrm{C} 7)$ & .832 & & & & & & & & & \\
\hline New product development cost $(\mathrm{C} 8)$ & .874 & & & & & & & & & \\
\hline Return on Asset (C14) & .764 & & & & & & & & & \\
\hline Operating cost (C15) & .874 & & & & & & & & & \\
\hline Manufacturing cost (C16) & .875 & & & & & & & & & \\
\hline Setup cost (C17) & .844 & & & & & & & & & \\
\hline Inventory cost (C18) & .766 & & & & & & & & & \\
\hline Real-time monitoring of processes (F10) & & .892 & & & & & & & & \\
\hline Real-time job scheduling (F12) & & .829 & & & & & & & & \\
\hline Real-time labor efficiency prediction (F13) & & .774 & & & & & & & & \\
\hline Dynamic workstation assignments (F17) & & .768 & & & & & & & & \\
\hline Dynamic line balancing (F18) & & .906 & & & & & & & & \\
\hline Real-time detection of product failure (Q7) & & .661 & & & & & & & & \\
\hline Process visualization and control (Q8) & & .759 & & & & & & & & \\
\hline Early fault detection (Q11) & & .700 & & & & & & & & \\
\hline Machine state condition monitoring (Q12) & & .901 & & & & & & & & \\
\hline Energy consumption prediction (C13) & & .635 & & & & & & & & \\
\hline Overall equipment effectiveness (P2) & & & .758 & & & & & & & \\
\hline Optimized machining process (P7) & & & .661 & & & & & & & \\
\hline Optimized plant layout (P8) & & & .586 & & & & & & & \\
\hline Optimized use of materials (P9) & & & .632 & & & & & & & \\
\hline Optimized warehouse layout (P10) & & & .659 & & & & & & & \\
\hline Labor productivity (P12) & & & .712 & & & & & & & \\
\hline Warranty claims (Q2) & & & & .865 & & & & & & \\
\hline
\end{tabular}




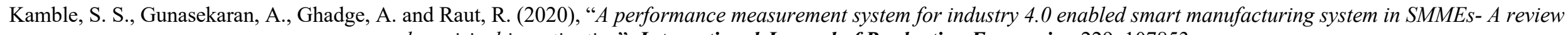
and empirical investigation”, International Journal of Production Economics, 229, 107853.

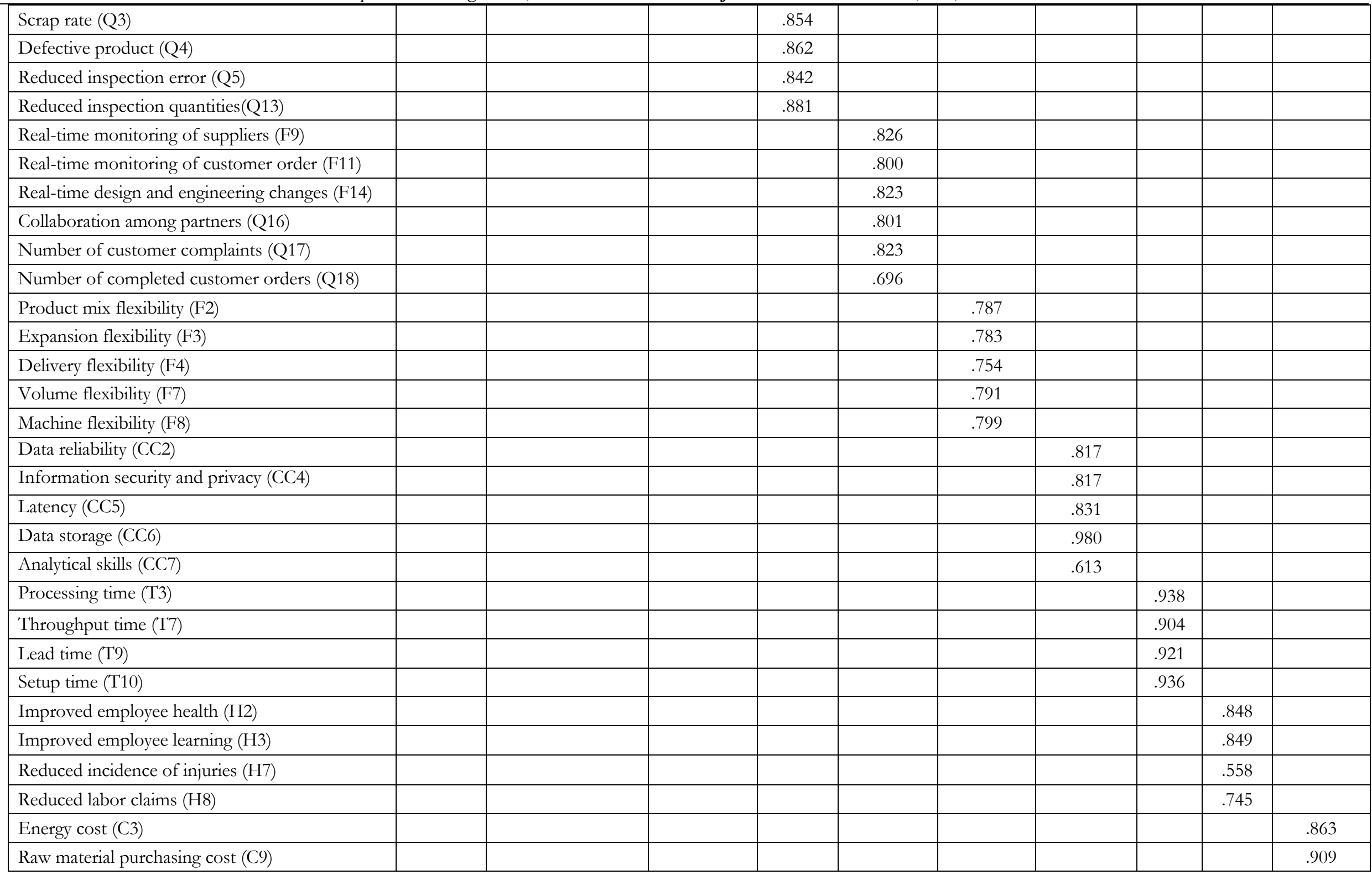




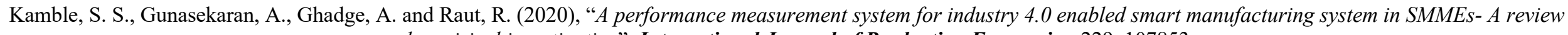
and empirical investigation", International Journal of Production Economics, 229, 107853.

Rework cost (C10)

Waste treatment cost $(\mathrm{C} 11)$ 
Kamble, S. S., Gunasekaran, A., Ghadge, A. and Raut, R. (2020), “A performance measurement system for industry 4.0 enabled smart manufacturing system in SMMEs- A review and empirical investigation", International Journal of

Production Economics, 229, 107853.

\subsection{Validation of the factor structure of performance measures}

Although the EFA established the convergent validity of the measurement items in Phase II; it was necessary to confirm the statistical significance of the measurement model involving 59 performance measures in 10 dimensions. The results presented in Table 5 indicated that the measurement items have no convergent validity concerns (CSR $>0.70$, and AVE $>0.50)$. Further, for all the constructs the square root AVE was higher than the correlations between that specific construct, and all the other constructs indicating that the performance dimensions had no discriminant validity issues (Cooper and Zmud, 1990; Hair et al., 2014). The CFA indicated a satisfactory model fit for the ten performance dimensions with positive degrees of freedom $=1280$, $\chi^{2}=3199.32, \chi^{2} / \mathrm{df}$ ratio $=2.49, \mathrm{CFI}=0.912, \mathrm{TLI}=0.897$, and $\mathrm{RMSEA}=0.081$. All the above findings indicated that the identified performance dimensions were unidimensional.

Table 5: Confirmatory and discriminant validity measures

\begin{tabular}{|c|c|c|c|c|c|c|c|c|c|c|c|c|}
\hline DIMENSIONS & CSR & AVE & COST & RTFD & OP & QUAL & INT & FLEX & ECO & SOC & COMP & TIME \\
\hline COST & 0.959 & 0.747 & $\mathbf{0 . 8 6 4}$ & & & & & & & & \\
\hline RTPD & 0.933 & 0.646 & $0.333^{* * *}$ & $\mathbf{0 . 8 0 3}$ & & & & & & & & \\
\hline OP & 0.976 & 0.852 & $0.595^{* * *}$ & $0.415^{* * *}$ & $\mathbf{0 . 9 2 3}$ & & & & & & & \\
\hline QUAL & 0.981 & 0.929 & $0.372^{* * *}$ & $0.266^{* *}$ & $0.690^{* * *}$ & $\mathbf{0 . 9 6 4}$ & & & & & & \\
\hline INT & 0.985 & 0.916 & $0.530^{* * *}$ & $0.355^{* * *}$ & $0.687^{* * *}$ & $0.567 * * *$ & $\mathbf{0 . 9 5 7}$ & & & & & \\
\hline FLEX & 0.976 & 0.910 & $0.521^{* * *}$ & $0.523^{* * *}$ & $0.609^{* * *}$ & $0.408^{* * *}$ & $0.484^{* * *}$ & $\mathbf{0 . 9 5 4}$ & & & & \\
\hline ECO & 0.876 & 0.648 & $0.372^{* * *}$ & $0.261^{* *}$ & $0.332^{* * *}$ & 0.103 & $0.289^{* * *}$ & $0.282^{* * *}$ & $\mathbf{0 . 8 0 5}$ & & & \\
\hline SOC & 0.910 & 0.725 & $0.182^{* * *}$ & 0.045 & $0.171^{* * *}$ & $0.098^{* *}$ & $0.187^{* * *}$ & $0.129^{* * *}$ & $0.141 * * *$ & $\mathbf{0 . 8 5 2}$ & & \\
\hline COMP & 0.766 & 0.541 & 0.067 & 0.078 & 0.167 & 0.071 & $0.214^{*}$ & 0.059 & 0.165 & 0.063 & $\mathbf{0 . 7 3 5}$ & \\
\hline TIME & 0.944 & 0.809 & 0.006 & 0.006 & 0.087 & 0.060 & 0.028 & 0.053 & 0.005 & 0.003 & 0.026 & $\mathbf{0 . 8 9 9}$ \\
\hline
\end{tabular}

Significance of Correlations:

${ }^{*} p<0.050$, ** $p<0.010$, *** $p<0.001$

RTFD: Real-time diagnosis and prognosis, OP: Optimized productivity, QUAL: Quality, INT: Integration, FLEX: Flexibility, ECO: Ecological Sustainability, SOC: Social Sustainability, COMP: Computing,

\section{Discussion and implications}

This study presented relevant performance measures and a performance measurement system that can be used for the assessment of SMS investments in SMMEs. The measures were identified using a combination of the exploratory and empirical validation process in the auto-component manufacturing sector. The study found that the SMMEs are convinced that the implementation of SMS will provide them with the competitive benefits of improved costs, quality, time, flexibility, optimized productivity, real-time diagnosis and prognosis, computing performance, integration, 
Kamble, S. S., Gunasekaran, A., Ghadge, A. and Raut, R. (2020), “A performance measurement system for industry 4.0 enabled smart manufacturing system in SMMEs- A review and empirical investigation", International Journal of

Production Economics, 229, 107853.

social, and ecological sustainability dimensions. SMS contributes to achieving improvements in the overall performance of the organization. Tortorella et al. (2020) identified that emerging technologies lead to an improvement in the quality of the products and customer service level satisfaction, thereby increasing the overall efficiency of the organization. However, to achieve these benefits, organizations are required to create an environment of learning and knowledge sharing. The present study statistically validated ten performance dimensions. These measures can be used by the practitioners to evaluate their SMS and build a performance-oriented manufacturing system.

In this section, we first discuss the findings, including implications for theory and practice. Following this, a smart manufacturing performance measurement system (SMPMS) is proposed which is expected to guide practitioners from the SMMEs to plan, measure, and control their SMS for the improved performance.

\subsection{Theoretical implications}

The SMMEs significantly contributes to the economic and regional development of a country. SMMEs are continually looking forward to enhancing their competitiveness by adopting innovative technological solutions. However, during the implementation of these technologies, SMMEs face issues related to economic, social, and ecological sustainability that discourages them from proceeding with the investments. The previous studies in the literature have focused on identifying the implementation drivers and barriers of such technologies in SMMEs; however, they fail to provide a comprehensive system to guide and evaluate the implementation (Kamble et al., 2018a). The main contribution of this study is to identify and develop a complete system that guides the implementation of Industry 4.0 enabled SMS in SMMEs. The Smart Manufacturing Performance Measurement System framework (presented below) is novel contribution of the study. The study extends the literature in two significant ways. Firstly, it contributes to the research of SMMEs by offering a performance measurement system that can be used to guide and evaluate the investments in innovative technologies such as Industry 4.0. Secondly, it extends the literature on Industry 4.0 by identifying a set of empirically validated performance measures to evaluate SMS performance. It is expected that the findings of the study will lead to more focused research on innovative technology evaluations and investment opportunities in SMMEs.

\subsection{Managerial Implications}

The 'cost' have been one of the critical performance criteria, which finds its origin from the discipline of cost accounting. This study found ten significant cost measures that are related to the productivity and efficiency of the organizations and provide a straightforward interpretation of 
Kamble, S. S., Gunasekaran, A., Ghadge, A. and Raut, R. (2020), “A performance measurement system for industry 4.0 enabled smart manufacturing system in SMMEs- A review and empirical investigation", International Journal of

Production Economics, 229, 107853.

SMS performance. The quality measures focused on the objective parameters such as scrap, defects, and inspection quantities. The quality measures identified for evaluation of SMS investments were less in number compared to the conventional manufacturing systems, because SMS enables continuous monitoring and control of the products, processes and actors that lead to reduced quality issues. Although the exploratory study had identified twenty measures under the quality dimension, the empirical validation clustered many of these measures to form new dimensions such as real-time diagnosis \& prognosis and optimized productivity, which were not observed in the previous studies. Similar findings were observed for the flexibility measures wherein only five out of eighteen measures identified in the exploratory phase were retained in the empirical validation. The measures in the optimized productivity dimension focused on the optimized use of resources such as labor, materials and machines.

The integration dimension evaluates the extent of influence SMS has on improved internal and external relationships. The finding implies that SMS should use a suitable IoT platform to integrate the suppliers, distributed manufacturing services, and manufacturing facilities to reduce the complicated manufacturing tasks. The IoT based SMS enables collaboration between the manufacturing services that are geographically distributed; and optimize the logistics routes on the dimensions of time, cost, and reliability (Wang et al., 2019b). The Industry 4.0 paradigm supported by CPS offers the SMS promising capabilities leading to effective and flexible manufacturing. It is implied that to exploit the benefits of collaborative sharing and networked manufacturing resources, the organizations should focus on automatic control of manufacturing equipment adaptively and effectively (Adamson et al., 2017).

Blockchain technology is recommended for reducing information asymmetry, which has led to overcoming the issues of trust and collaboration among the supply chain partners (Longo et al., 2019; Kamble et al., 2020b). Blockchain adoption discourages counterfeiting of data and poor information quality, which have a negative influence on manufacturing performance. The use of blockchain, together with other technologies such as IoT and big data, can provide manufacturing organizations the benefit of traceability, information security, and sustainable manufacturing (Kamble et al., 2019a). However, for effective implementation of blockchain, the organizations will be required to overcome the barriers of information storage capacity and scalability, high cost of implementation, regulatory issues, and lack of skills (Zhao et al., 2019; Kamble et al., 2019a; 2019b).

The Industry 4.0 technologies and architectures are expected to perform high on parameters of latency and reliability or resilience of cyber-physical interfaces. These interfaces support SMS applications required for data storage, analysis, and transfer (Zhou and Yao, 2017). 
Kamble, S. S., Gunasekaran, A., Ghadge, A. and Raut, R. (2020), “A performance measurement system for industry 4.0 enabled smart manufacturing system in SMMEs- A review and empirical investigation", International Journal of

Production Economics, 229, 107853.

The measures identified in the computing performance dimension implies that the SMMEs should consider beyond cloud computing technology and consider the decentralized fog computing architectures to provide higher data consistency, reliability, privacy, and security (Chekired et al., 2018; O'Donovan et al., 2019). Fog computing is found to be an efficient technology for enabling real-time monitoring and control, reducing the delay in transmitting the information, reduced energy consumption, improved memory utilization, and throughput (Wu et al., 2017). The SMMEs have to develop an efficient computing system to provide a high level of controllability and security from vulnerable cyber-attack (Khalid et al., 2018). Frameworks based on edge computing and artificial intelligence are found to improve the resource efficiency of computing services and improve the quality of diagnostic and prognostic performance in SMS (Li et al., 2019). The SMMEs should consider moving some critical services and data from the centralized data server to the data source for enhanced computational efficiency (Yen et al., 2019) and consider use of proactive caching strategy in edge computing environment for improved goodput and real-time performance (Li et al., 2019).

The results of the study also identified the need to evaluate SMS investments on the benefits of social and environmental sustainability. With the evolution of emerging technologies, the major challenge for organizations is to integrate people within the CPS. The finding implies that SMS must include the unique characteristics of the human labor and the CPS, addressing various scenarios of irregularities such as detection of machine failure or identification of process bottlenecks and guide the managers in developing human resource strategy (Fantini et al., 2018). Industry 4.0 capabilities offer an adaptive, continuous interaction between the operator and the machines improving operator safety, performance, well-being, and satisfaction (Golan et al., 2019). The SMMEs should use immersive interface systems such as AR, VR based systems, process mining tools, and expert guidance received from the knowledgeable workers to improve the performance of the product assemblies (Roldán et al., 2019). The innovative virtual prototypes consisting of eye-tracking and wearable sensor devices are being developed for improved interactions between the workers and the digital factory. Such a human-machine interaction system should be formed by SMMEs to assist in the improvement and optimization of shop-floor operation, process workflow, workstation design, and layout (Peruzzini et al., 2019). The other developments which should be considered by the MSMEs to improve work performance and reduce the worker's anxiety include use of collaborative robots (Eimontaite et al., 2019), wearable digital assembly gloves to find defective products and processes using the vibrations and force values on the fingers ((Eimontaite et al., 2019) 
Kamble, S. S., Gunasekaran, A., Ghadge, A. and Raut, R. (2020), “A performance measurement system for industry 4.0 enabled smart manufacturing system in SMMEs- A review and empirical investigation", International Journal of

Production Economics, 229, 107853.

The emerging technologies provide an overload of environmental information to the SMMEs. The main challenge for the SMMEs is to select the relevant ecological data and relate it to the productivity of the organization (Santos et al., 2019). High consumption of energy acts as a critical barrier for the use of industrial robots in SMS, affecting the manufacturing process sustainability. It is, therefore, essential to reduce the energy efficiency of the robotic cell, maintaining high productivity levels and manufacturing quality (Gadaleta et al., 2019). SMMEs should realize the role played by IoT in analyzing the remaining life of the assets, plan product warranty and maintenance schedules of the remanufactured products (Alqahtani et al., 2019; Meng et al., 2018; Pistolesi et al., 2018).

The twelve performance measures identified in the real-time diagnosis \& prognosis dimension focused on proactive performance management. The study implies that the SMS has replaced most of the diagnostic analysis that is based on an off-line review, human intervention, relying mainly on the past experience of the operator and knowledge on the known parameters (Lu et al., 2019). The SMS uses powerful data-driven prognosis techniques that are more agile and adaptable to complex situations (Bagheri, 2018; Jung et al., 2015; Kamble et al., 2020a). The SMMEs may consider the use of image processing techniques to automate the observation and evaluation of the manufacturing process (Zhao et al., 2017) and fault diagnosis (Fu et al., 2019). Machine learning algorithms and artificial intelligence are found to be highly useful to predict process performance (Huang et al., 2019; Jia et al., 2015). The real-time monitoring capabilities provide SMMEs with insights into possible states, operating, and failure modes that can occur and support the improvement of the existing manufacturing processes (Rivera Torres et al., 2018). Learning effects can be exploited for preparing batches by grouping customized orders based on similarities in the production process, reducing the average throughput time (Castellano et al., 2019). The existing planning and scheduling methods in mixed-model production industries are not efficient enough to be utilized in SMS. There is a need to update the plan and schedule in realtime (Saif et al., 2019). The simultaneous rate for the arrival of orders and the product delivery schedule in SMS are identified as the two significant complexities in scheduling (Fan et al., 2019). Efficient scheduling systems result in a reduced number of works in process and less pressure on the buffer. One of the important aspects of SMS is regarding when and how the information is used for decision making. The real-time information on the completion of jobs may be used for rescheduling of jobs. However, the SMMEs should understand that the efficiency of these schedules will be dependent on the variability in the processing time and the quality of the initially generated schedules (Framinan et al., 2019). 
Kamble, S. S., Gunasekaran, A., Ghadge, A. and Raut, R. (2020), “A performance measurement system for industry 4.0 enabled smart manufacturing system in SMMEs- A review and empirical investigation", International Journal of Production Economics, 229, 107853.

The diagnosis \& prognosis measures also support redundancy planning and reducing the quality inspections at the manufacturing shop floor. Renna (2019) suggests that the cyber-physical interface, combined with the use of artificial intelligence and self-adapting activities, can enable a station of the automated flow line, reducing the time consuming and costly setups for the SMMEs. Quality control is a crucial aspect of any manufacturing organization and includes product inspection at different stages of manufacturing. The SMMEs with the investments in the SMS can aim to minimize the inspection cost, improve the outgoing quality, and reduce inspection requirements (Kang et al., 2018). The time consuming and costly product qualification testing, which is performed using conventional standards and user-defined requirements, can be made efficient by using predictive analytics (Stoyanov et al., 2019).

The above discussions and implications provide valuable information to the SMMEs on the crucial performance dimensions and the measures they need to consider for managing SMS performance. Based on the above discussions and implications of the study, a general framework on how to use the identified performance measures and evaluate the SMS performance is presented in the following section.

\section{Smart Manufacturing Performance Measurement System}

The study identified ten performance dimensions, namely, cost, quality, flexibility, time, integration, optimized productivity, real-time diagnosis \& prognosis, computing, social and ecological sustainability, that can be considered as the competitive benefits resulting from an investment in SMS. Based on above findings, this study proposes a Smart Manufacturing Performance Measurement System (SMPMS) framework. The framework presented in Fig. 3 is expected to guide SMMEs in evaluating SMS investments. 
Kamble, S. S., Gunasekaran, A., Ghadge, A. and Raut, R. (2020), “A performance measurement system for industry 4.0 enabled smart manufacturing system in SMMEs-A review and empirical investigation", International Journal of Production Economics, 229, 107853.

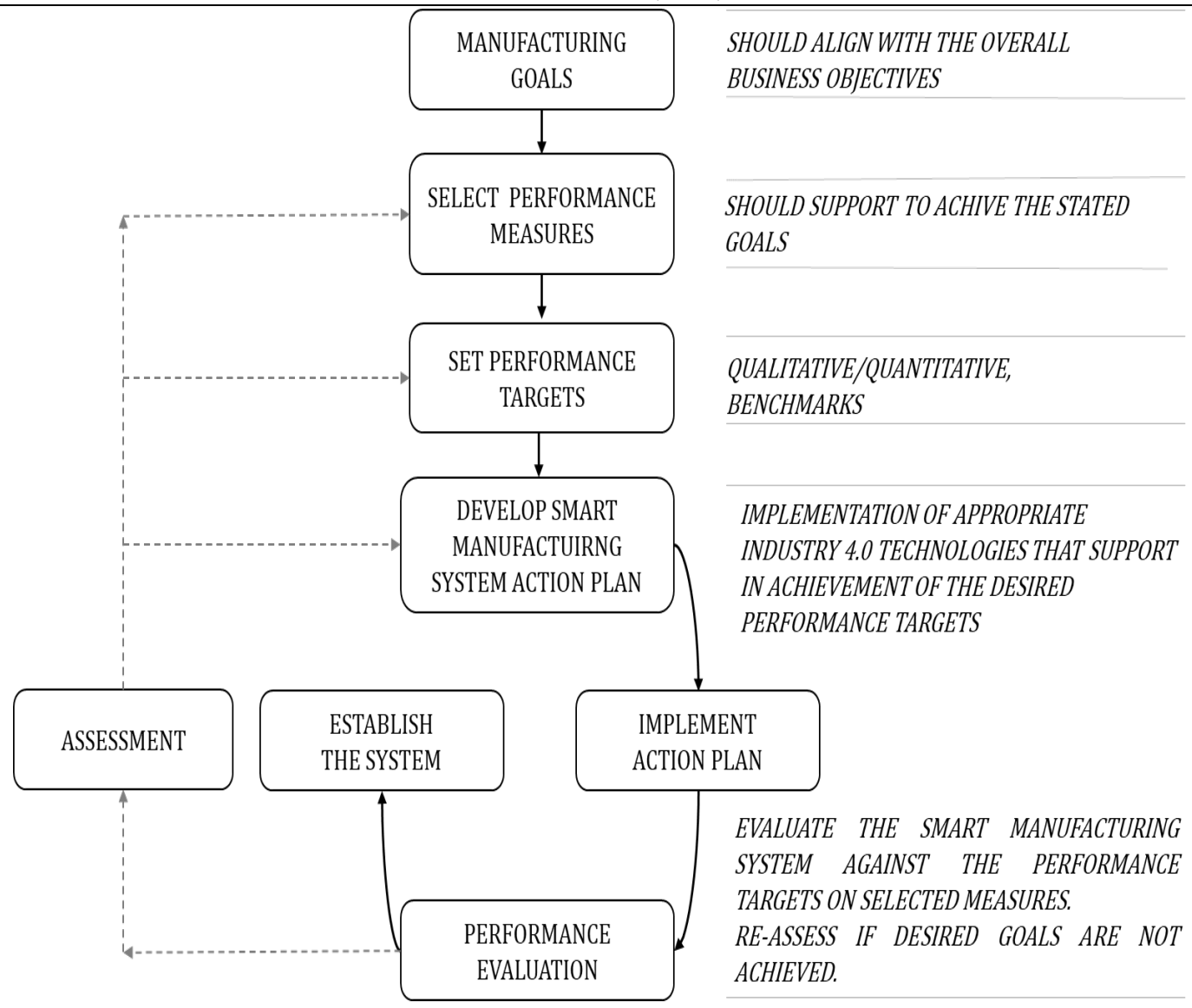

Figure 2: A Smart Manufacturing Performance Measurement System

Although the study was specific to auto-component manufacturers, the SMPMS framework can be used by any Industry after validating these performance dimensions. The study found that the benefits offered by SMS are far more significant than the narrow focus of traditional manufacturing systems on dimensions of cost, quality, flexibility, and optimized productivity. The SMPMS framework proposes that the evaluation considers the impact of SMS on all the ten performance dimensions relative to their importance to achieving the business objectives. Typically, there will be trade-offs engaged in adopting an SMS. For e.g., an SMMEs may consider implementing AR for employee training. This may improve the performance of the SMMEs in developing an excellent social eco-system with satisfied employees and non-invasive machine interaction. However, this may impact the SMMEs more by increased cost than is gained by the development of a social eco-system. Once the SMMEs selects the appropriate performance dimensions, the next step is to set the performance target using suitable performance measures from Table 4. Usually, several performance measures are needed to describe broader or more aggregated performance dimensions adequately. The performance targets are set against historical standards, future improvement goals or level of competition in market. The manufacturing goals 
Kamble, S. S., Gunasekaran, A., Ghadge, A. and Raut, R. (2020), “A performance measurement system for industry 4.0 enabled smart manufacturing system in SMMEs- A review and empirical investigation", International Journal of

Production Economics, 229, 107853.

and the performance targets guide the development of an SMS action plan, that may involve the implementation of Industry 4.0 technologies such as IoT, Blockchain, additive manufacturing, Big data analytics, AR/VR, etc. On application, the performance targets are needed to be closely monitored continuously and any deviations from the manufacturing goals should be addressed with an improvement plan.

A brief illustration of the SMPMS framework is presented below.

\section{Manufacturing goals}

The manufacturing goals should be aligned with the overall business objectives of the SMMEs and should be guided by the competitive benefit the SMMEs would like to achieve. The manufacturing goals could be one or several performance dimensions. However, the decision-maker should take care that the selected dimensions are not conflicting with each other. For e.g., Integration would be the most appropriate manufacturing goal for SMMEs to address the changing needs of the customer proactively. Accordingly, the SMMEs may also select real-time diagnosis \& prognosis as the supporting goal to become highly proactive.

\section{Performance Measures}

The relevant measures to evaluate the performance of SMMEs for achieving the manufacturing goals should be selected (Refer to Table 4). For e.g., most of the measures would be selected from the integration dimension; however, relevant measures from the dimensions of real-time diagnosis \& prognosis and computing performance will also be chosen. Let us assume that the SMMEs decides to select the measures real-time design \& engineering changes, real-time monitoring of suppliers, real-time monitoring of customer orders, dynamic line balancing, and dynamic order allocation to react proactively to their customers.

\section{Performance targets}

The targets set for the performance measures should be measurable and realistic. These performance targets should be communicated to all the functional managers to guide their operational decisions. This will help the SMMEs to collect all the relevant information for performance evaluation without any disruption. For e.g. the SMMEs may want to achieve dynamic order allocations to be executed in 20 minutes.

SMS action plan

In SMPMS, the action plan revolves around the implementation of suitable Industry 4.0 technology to develop SMS. For e.g., the best action plan to achieve the performance targets on the measures of real-time design \& engineering changes, real-time monitoring of suppliers, realtime monitoring of customer orders, dynamic line balancing, and dynamic order allocation could 
Kamble, S. S., Gunasekaran, A., Ghadge, A. and Raut, R. (2020), “A performance measurement system for industry 4.0 enabled smart manufacturing system in SMMEs- A review and empirical investigation", International Journal of

Production Economics, 229, 107853.

be to implement a system involving additive manufacturing, IoT, cloud computing and big data analytics.

Performance evaluation and monitoring

The performance evaluation and monitoring are done by comparing the actual performance with the target performance as per the schedule. Based on the assessment, the SMMEs may come across the following situations.

- No change in the performance measures, targets, and the SMS action plan: This is possible when the selected measures and targets contribute towards the achievement of manufacturing goals without deviation.

- Removal or revision of performance measures: The SMMEs may identify after the first stage of evaluation that few measures need to be replaced or removed, as they are found to be irrelevant or insignificant with no contribution to the manufacturing goals.

- Revision in performance targets: The SMMEs may realize that the set targets are not measurable due to the unavailability of relevant information or they are unrealistic. In such scenarios, the targets need to be revised.

Following above structured approach, it is believed that the SMPMS will support the SMMEs in developing a robust SMS, aligned with the manufacturing goals and the business objectives.

\section{$7 \quad$ Limitations and future research}

SMS is different from the traditional manufacturing systems in terms of the way operations are performed, quality is checked, maintenance is performed and employees' relationships are developed; and therefore, requires different measures for performance evaluation. The study had few limitations, which provides opportunities for future research.

Although the study setup is based on the India-based empirical data, India is a unique economy being one of the largest economies in Asia, with a large number of SMMEs, and many diaspora Indian entrepreneurs scattered around Asia and the Globe, there is some potential for generalizability, albeit this is not the main objective of the study. Nonetheless, focus on India creates significant future research opportunities for scholars, and we invite them to test the measures in other economies in and outside Asia.

The measures used in this study are statistically validated using data collected from mediumsized auto-component manufacturing organizations based in India. Therefore, it would be necessary to conduct similar studies and confirm the findings in other industries such as pharmaceuticals, chemicals, FMCG, etc. It would also be interesting to find out which 
Kamble, S. S., Gunasekaran, A., Ghadge, A. and Raut, R. (2020), “A performance measurement system for industry 4.0 enabled smart manufacturing system in SMMEs- A review and empirical investigation", International Journal of Production Economics, 229, 107853.

performance dimensions are more powerful or more fundamental than others while evaluating SMS.

The SMS is a change initiative and needs different technologies such as IoT, cloud computing, CPS to be implemented. Therefore, SMS implementations will differ from one organization to the next due to differences in the market being served, technological maturity, competitive and regulatory environment. The previous studies have identified barriers to implementation of SMS and provided solutions to overcome them (Kamble et al., 2018b). However, it is presumed that SMS being a huge transformation process, it is sure to be influenced by the organizational culture, its values, and traditions. The present study has not considered this aspect, requiring future studies to investigate the influence of organizational culture on SMS performance and provide insights on how to measure them for effective implementation of SMS.

The study identified a set of sustainable dimensions, namely, social and ecological, that influence the SMS. However, the extent of influence these measures have on the SMS is dependent on the existing practices of the organizations. The literature reveals that lean and circular economy practices provide a facilitating environment for Industry 4.0 and data-driven supply chains, leading to sustainable organizational performance (Kamble et al., 2019; Belhadi et al., 2020). Therefore, it would be interesting to investigate how the identified performance measure dimensions are used in organizations with different levels of lean and circular economy practices. 
Kamble, S. S., Gunasekaran, A., Ghadge, A. and Raut, R. (2020), “A performance measurement system for industry 4.0 enabled smart manufacturing system in SMMEs-A review and empirical investigation”, International Journal of Production Economics, 229, 107853.

\section{$\underline{\text { References }}$}

Alqahtani, A. Y., Gupta, S. M., \& Nakashima, K. (2019). Warranty and maintenance analysis of sensor embedded products using internet of things in industry 4.0. International Journal of Production Economics, 208, 483-499. https://doi.org/10.1016/j.ijpe.2018.12.022

Ante, G., Facchini, F., Mossa, G., \& Digiesi, S. (2018). Developing a key performance indicators tree for lean and smart production systems. IFAC-PapersOnLine, 51(11), 13-18.

Arcot, R. Move over, IT: IIoT is the next big thing for SMMESs. 2017. Available at: https://economictimes.indiatimes.com/small-biz/sme-sector/move-over-it-iiot-is-the-next-big-thing-forSMMEss/articleshow/57040654.cms?from $=\mathrm{mdr}$

Bagheri, M., Zollanvari, A., \& Nezhivenko, S. (2018). Transformer fault condition prognosis using vibration signals over cloud environment. IEEE Access, 6, 9862-9874.

Bányai, Á., Illés, B., Glistau, E., Machado, N. I. C., Tamás, P., Manzoor, F., \& Bányai, T. (2019). Smart cyber-physical manufacturing: Extended and real-time optimization of logistics resources in matrix production. Applied Sciences, 9(7), 1287.

Bauters, K., Cottyn, J., Claeys, D., Slembrouck, M., Veelaert, P., \& Van Landeghem, H. (2018). Automated work cycle classification and performance measurement for manual workstations. Robotics and Computer-Integrated Manufacturing, 51, 139-157.

Beamon, B. M. (1999). Measuring SC Performance. International Journal of Operations \& Production Management 19 (3): 275-292.

Belhadi, A., Kamble, S. S., Zkik, K., Cherrafi, A., \& Touriki, F. E. (2020). The integrated effect of Big Data Analytics, Lean Six Sigma and Green Manufacturing on the environmental performance of manufacturing companies: The case of North Africa. Journal of Cleaner Production, 252, 119903.

Biondi, M., Sand, G., Harjunkoski, I. (2017). Optimization of multipurpose process plant operations: A multi-timescale maintenance and production scheduling approach. Computers and Chemical Engineering, 99, pp. 325-339.

Bititci, U. S., Mendibil, K., Martinez, V., \& Albores, P. (2005). Measuring and managing performance in extended enterprises. International Journal of Operations \& Production Management, 25(4), 333-353.

Blanco-Novoa, O., Fernández-Caramés, T. M., Fraga-Lamas, P., \& Vilar-Montesinos, M. A. (2018). A practical evaluation of commercial industrial augmented reality systems in an industry 4.0 shipyard. IEEE Access, 6, 82018218.

Bordel, B., \& Alcarria, R. (2017). Assessment of human motivation through analysis of physiological and emotional signals in Industry 4.0 scenarios. Journal of Ambient Intelligence and Humanized Computing, 1-21. DOI: 10.1007/s12652017-0664-4

Bouzary, H., \& Chen, F. F. (2019). A hybrid grey wolf optimizer algorithm with evolutionary operators for optimal QoS-aware service composition and optimal selection in cloud manufacturing. The International Journal of Advanced Manufacturing Technology, 101(9-12), 2771-2784.

Büyüközkan, G., \& Göçer, F. (2018). Digital Supply Chain: Literature review and a proposed framework for future research. Computers in Industry, 97, 157-177.

Carvajal Soto, J. A., Tavakolizadeh, F., \& Gyulai, D. (2019). An online machine learning framework for early detection of product failures in an Industry 4.0 context. International Journal of Computer Integrated Manufacturing, 32(4-5), 452465.

Castellano, D., Gallo, M., Grassi, A., \& Santillo, L. C. (2019). Batching decisions in multi-item production systems with learning effect. Computers \& Industrial Engineering, 131, 578-591.

Chan, F. T. 2003. "Performance Measurement in a SC." The International Journal of Advanced Manufacturing Technology 21 (7):534-548.

Chauhan, C., Sharma, A., \& Singh, A. (2019). A SAP-LAP linkages framework for integrating Industry 4.0 and circular economy. Benchmarking: An International Journal. DOI: 10.1108/BIJ-10-2018-0310

Chen, C., Liu, Y., Kumar, M., Qin, J., \& Ren, Y. (2019). Energy consumption modelling using deep learning embedded semi-supervised learning. Computers \& Industrial Engineering, 135, 757-765.DOI: 10.1016/j.cie.2019.06.052

Chen, Z. Y., \& Kuo, R. J. (2019). Combining SOM and evolutionary computation algorithms for RBF neural network training. Journal of Intelligent Manufacturing, 30(3), 1137-1154..

Child, D. (1990). The essentials of factor analysis, second edition. London: Cassel Educational Limited.

Cooper, R. B., and R. W. Zmud. 1990. "Information Technology Implementation Research: A Technological Diffusion Approach.” Management Science 36 (2): 123-139.

Curran, P. J., S. G.West, and J. F. Finch. 1996. "The Robustness of Test Statistics to Nonnormality and Specification Error in Confirmatory Factor Analysis." Psychological Methods 1 (1): 16-29.

Curran, P. J., S. G.West, and J. F. Finch. 1996. "The Robustness of Test Statistics to Nonnormality and Specification Error in Confirmatory Factor Analysis.” Psychological Methods 1 (1): 16-29.

Davis, J., Edgar, T., Porter, J., Bernaden, J., \& Sarli, M. (2012). Smart manufacturing, manufacturing intelligence and demand-dynamic performance. Computers and Chemical Engineering, 47, 145-156. https://doi.org/10.1016/j.compchemeng.2012.06.037 
Kamble, S. S., Gunasekaran, A., Ghadge, A. and Raut, R. (2020), “A performance measurement system for industry 4.0 enabled smart manufacturing system in SMMEs- A review and empirical investigation", International Journal of Production Economics, 229, 107853.

Delbrügger, T., Meißner, M., Wirtz, A., Biermann, D., Myrzik, J., Rossmann, J., \& Wiederkehr, P. (2019). Multi-level simulation concept for multidisciplinary analysis and optimization of production systems. The International Journal of Advanced Manufacturing Technology, 103(9-12), 3993-4012. DOI: 10.1007/s00170-019-03722-1

DeVellis, R. F. (1991). Scale Development: Theory and Applications. Newbury Park, California: Sage Publications.

Dick, W. and Hagerty, N. (1971), Topics in Measurement \pm Reliability and Validity, McGraw-Hill, New York, NY.

Diego Fernando, M. D., \& Rivera Cadavid, L. (2007). Lean manufacturing measurement: the relationship between lean activities and lean metrics. Estudios Gerenciales, 23(105), 69-83. https://doi.org/10.1016/s01235923(07)70026-8

Dillon, W.R. and Goldstein, M. (1984), Multivariate Analysis \pm Methods and Applications, John Wiley \& Sons, New York, NY

Edgar, T. F., \& Pistikopoulos, E. N. (2018). Smart manufacturing and energy systems. Computers and Chemical Engineering, 114, 130-144. https://doi.org/10.1016/j.compchemeng.2017.10.027

Eimontaite, I., Gwilt, I., Cameron, D., Aitken, J. M., Rolph, J., Mokaram, S., \& Law, J. (2019). Language-free graphical signage improves human performance and reduces anxiety when working collaboratively with robots. The International Journal of Advanced Manufacturing Technology, 100(1-4), 55-73. DOI: 10.1007/s00170-018-2625-2

Emmer, C., Hofmann, T. M., Schmied, T., Stjepandić, J., \& Strietzel, M. (2018). A neutral approach for interoperability in the field of 3D measurement data management. Journal of Industrial Information Integration, 12, 47-56.

Fan, B., Yang, W., Zhang, Z. (2019).Solving the two-stage hybrid flow shop scheduling problem based on mutant firefly algorithm. Journal of Ambient Intelligence and Humanized Computing, 10 (3), pp. 979-990. DOI: 10.1007/s12652018-0903-3

Fan, Y., Chen, J., Shirkey, G., John, R., Wu, S. R., Park, H., \& Shao, C. (2016). Applications of structural equation modeling (SEM) in ecological studies: an updated review. Ecological Processes, 5(1), 19.

Fantini, P., Pinzone, M., Taisch, M. (2018). Placing the operator at the centre of Industry 4.0 design: Modelling and assessing human activities within cyber-physical systems. Computers and Industrial Engineering. DOI: 10.1016/j.cie.2018.01.025

Flynn, B.B., Sakakibara, S., Schroeder, R.G., Bates, K.A. and Flynn, J.B. (1990), “Empirical research methods in operations management", Journal of Operations Management, 9(2), pp. 250-84.

Framinan, J.M., Fernandez-Viagas, V., Perez-Gonzalez, P. (2019). Using real-time information to reschedule jobs in a flowshop with variable processing times. Computers and Industrial Engineering, 129, pp. 113-125. DOI: 10.1016/j.cie.2019.01.036

Frederico, G.F., Garza-Reyes, J.A., Anosike, A. and Kumar, V. (2019), "Supply Chain 4.0: concepts, maturity and research agenda", Supply Chain Management, Vol. 25 No. 2, pp. 262-282. https://doi.org/10.1108/SCM-09-20180339

Frederico, G.F., Garza-Reyes, J.A., Kumar, A. and Kumar, V. (2020), "Performance measurement for supply chains in the Industry 4.0 era: a balanced scorecard approach", International Journal of Productivity and Performance Management, Vol. ahead-of-print No. ahead-of-print. https://doi.org/10.1108/IJPPM-08-2019-0400

Fu, Y., Ding, J., Wang, H., Wang, J. (2018). Two-objective stochastic flow-shop scheduling with deteriorating and learning effect in Industry 4.0-based manufacturing system. Applied Soft Computing Journal, 68, pp. 847-855.

Fu, Y., Zhang, Y., Gao, H., Mao, T., Zhou, H., Sun, R., Li, D. (2019). Automatic feature constructing from vibration signals for machining state monitoring. Journal of Intelligent Manufacturing, 30 (3), pp. 995-1008.

Gadaleta, M., Pellicciari, M., Berselli, G. (2019). Optimization of the energy consumption of industrial robots for automatic code generation. Robotics and Computer-Integrated Manufacturing, 57, pp. 452-464. DOI: 10.1016/j.rcim.2018.12.020

Gamberini, R., Galloni, L., Lolli, F., Rimini, B. (2017). On the Analysis of Effectiveness in a Manufacturing Cell: A Critical Implementation of Existing Approaches. Procedia Manufacturing, 11, pp. 1882-1891.

Gawankar, S. A., Gunasekaran, A., \& Kamble, S. (2020). A study on investments in the big data-driven supply chain, performance measures and organisational performance in Indian retail 4.0 context. International Journal of Production Research, 58(5), 1574-1593.

Ghadge, A., Kara, M. E., Moradlou, H., \& Goswami, M. (2020). The impact of Industry 4.0 implementation on supply

chains. Journal of Manufacturing Technology Management, 31(4), pp.669-686. F

Giorgio Bort, C.M., Leonesio, M., Bosetti, P. (2016). A model-based adaptive controller for chatter mitigation and productivity enhancement in CNC milling machines. Robotics and Computer-Integrated Manufacturing, 40, pp. 34-43.

Giusti, F., Bevilacqua, M., Tedeschi, S., \& Emmanouilidis, C. (2018). Data analytics and production efficiency evaluation on a flexible manufacturing cell. I2MTC 2018 - 2018 IEEE International Instrumentation and Measurement Technology Conference: Discovering New Horizons in Instrumentation and Measurement, Proceedings, 1-6. https://doi.org/10.1109/I2MTC.2018.8409677

Golan, M., Cohen, Y., Singer, G. (2019). A framework for operator- workstation interaction in Industry 4. International Journal of Production Research. DOI: 10.1080/00207543.2019.1639842

Gosselin, M. (2005). An empirical study of performance measurement in manufacturing firms. International Journal of Productivity and Performance Management, 54(5-6), 419-437. https://doi.org/10.1108/17410400510604566 
Kamble, S. S., Gunasekaran, A., Ghadge, A. and Raut, R. (2020), “A performance measurement system for industry 4.0 enabled smart manufacturing system in SMMEs- A review and empirical investigation", International Journal of Production Economics, 229, 107853.

Kara, M. E., Firat, S. Ü. O., \& Ghadge, A. (2020). A data mining-based framework for supply chain risk management. Computers \& Industrial Engineering, 139, 105570.

Gunasekaran, A., C. Patel, and E. Tirtiroglu. 2001. "Performance Measures and Metrics in a SC Environment." International Journal of Operations \&amp; Production Management 21 (1/2): 71-87.

Hair, J., W. Black, B. Y. A. Babin, R. Anderson, and R. Tatham. 2014. Multivariate Data Analysis. A Global Perspective. London, UK: Pearson Prentice Hall.

He, Q.P., Wang, J., Shah, D. (2019). Feature space monitoring for smart manufacturing via statistics pattern analysis. Computers and Chemical Engineering, pp. 321-331. DOI: 10.1016/j.compchemeng.2019.04.010

Hon, K. K. B. (2005). Performance and evaluation of manufacturing systems. CIRP Annals - Manufacturing Technology, 54(2), 139-154.

Hu, L., Bentler, P.M. (1999), "Cutoff Criteria for Fit Indexes in Covariance Structure Analysis: Conventional Criteria Versus New Alternatives" SEM vol. 6(1), pp. 1-55.

Hu, L., Miao, Y., Wu, G., Hassan, M.M., Humar, I. (2019). iRobot-Factory: An intelligent robot factory based on cognitive manufacturing and edge computing. Future Generation Computer Systems, 90, pp. 569-577.

Huang, J., Kong, L., Chen, G., Wu, M.-Y., Liu, X., Zeng, P. (2019). Towards secure industrial iot: Blockchain system with credit-based consensus mechanism. IEEE Transactions on Industrial Informatics, 15 (6), art. no. 8661654, pp. 3680-3689. DOI: 10.1109/TII.2019.2903342

Jia, Z., Zhao, K., Zhang, Y., Dai, Y., Liu, C. (2018). Real-time performance evaluation and improvement of assembly systems with Bernoulli machines and finite production runs. International Journal of Production Research. DOI: 10.1080/00207543.2018.1544426

Joreskog, K. G. (1969). A general approach to confirmatory maximum likelihood factor analysis, Psychometrika, 34, 183-202.

Jung, K., Morris, K.C., Lyons, K.W., Leong, S.W.E.E., Cho, H. (2015). Using formal methods to scope performance challenges for Smart Manufacturing Systems: Focus on agility. Concurrent Engineering Research and Applications, 23 (4), pp. 343-354.

Kamble, S. S., \& Gunasekaran, A. (2020). Big data-driven supply chain performance measurement system: a review and framework for implementation. International Journal of Production Research, 58(1), 65-86.

Kamble, S. S., Gunasekaran, A., \& Gawankar, S. A. (2018a). Sustainable Industry 4.0 framework: A systematic literature review identifying the current trends and future perspectives. Process Safety and Environmental Protection, 117, 408-425.

Kamble, S. S., Gunasekaran, A., \& Gawankar, S. A. (2020a). Achieving sustainable performance in a data-driven agriculture supply chain: A review for research and applications. International Journal of Production Economics, 219, 179194.

Kamble, S. S., Gunasekaran, A., \& Sharma, R. (2018b). Analysis of the driving and dependence power of barriers to adopt industry 4.0 in Indian manufacturing industry. Computers in Industry, 101, 107-119.

Kamble, S. S., Gunasekaran, A., \& Sharma, R. (2020b). Modeling the blockchain enabled traceability in agriculture supply chain. International Journal of Information Management, 52, 101967.

Kamble, S. S., Gunasekaran, A., Parekh, H., \& Joshi, S. (2019a). Modeling the internet of things adoption barriers in food retail supply chains. Journal of Retailing and Consumer Services, 48, 154-168.

Kamble, S., Gunasekaran, A., \& Arha, H. (2019b). Understanding the Blockchain technology adoption in supply chains-Indian context. International Journal of Production Research, 57(7), 2009-2033.

Kamble, S., Gunasekaran, A., \& Dhone, N. C. (2020c). Industry 4.0 and lean manufacturing practices for sustainable organisational performance in Indian manufacturing companies. International Journal of Production Research, 58(5), 1319-1337.

Kang, C.W., Ramzan, M.B., Sarkar, B., Imran, M. (2018). Effect of inspection performance in smart manufacturing system based on human quality control system. International Journal of Advanced Manufacturing Technology, 94 (9-12), pp. 4351-4364.

Khalid, A., Kirisci, P., Khan, Z.H., Ghrairi, Z., Thoben, K.-D., Pannek, J. (2018). Security framework for industrial collaborative robotic cyber-physical systems. Computers in Industry, 97, pp. 132-145.

Kiel, D., Arnold, C., \& Voigt, K. I. (2017a). The influence of the Industrial Internet of Things on business models of established manufacturing companies-A business level perspective. Technovation, 68, 4-19.

Kiel, D., Müller, J. M., Arnold, C., \& Voigt, K. I. (2017b). Sustainable industrial value creation: Benefits and challenges of industry 4.0. International Journal of Innovation Management, 21(08), 1740015.

KPMG-AIMA. (2018). Industry 4.0, India inc. gearing up for change. 2018. Available at: http://resources.aima.in/presentations/AIMA-KPMG-industry-4-0-report.pdf

Kucukoglu, I., Atici-Ulusu, H., Gunduz, T., Tokcalar, O. (2018). Application of the artificial neural network method to detect defective assembling processes by using a wearable technology. Journal of Manufacturing Systems, 49, pp. $163-171$. 
Kamble, S. S., Gunasekaran, A., Ghadge, A. and Raut, R. (2020), “A performance measurement system for industry 4.0 enabled smart manufacturing system in SMMEs- A review and empirical investigation", International Journal of Production Economics, 229, 107853.

Kumar, A., Chinnam, R.B., Tseng, F. (2019). An HMM and polynomial regression-based approach for remaining useful life and health state estimation of cutting tools. Computers and Industrial Engineering, 128, pp. 1008-1014. DOI: $10.1016 /$ j.cie.2018.05.017

Kumar, U., Galar, D., Parida, A., Stenström, C., \& Berges, L. (2013). Maintenance performance metrics: A state-ofthe-art review. Journal of Quality in Maintenance Engineering, 19(3), 233-277. https://doi.org/10.1108/JQME-052013-0029

Kusiak, A. (2019). Fundamentals of smart manufacturing: A multi-thread perspective. Annual Reviews in Control, 47(xxxx), 214-220. https://doi.org/10.1016/i.arcontrol.2019.02.001

Lapide, L. (2010). "Predictive Metrics." The Journal of Business Forecasting 29 (2): 23.

Lazarova-Molnar, S., Mohamed, N., \& Al-Jaroodi, J. (2018). Collaborative data analytics for industry 4.0: Challenges, opportunities and models. Proceedings - 2018 6th International Conference on Enterprise Systems, ES 2018, 100-107. https://doi.org/10.1109/ES.2018.00023

Lee, J. Lapira, E. (2013). Predictive factories: the next transformation, Manufacturing Leadership Journal, 20(1), pp. 1324.

Li, X., Wan, J., Dai, H.-N., Imran, M., Xia, M., Celesti, A. (2019). A Hybrid Computing Solution and Resource Scheduling Strategy for Edge Computing in Smart Manufacturing. IEEE Transactions on Industrial Informatics, 15 (7), art. no. 8643392, pp. 4225-4234. DOI: 10.1109/TII.2019.2899679

Liang, Y.C., Li, W.D., Lu, X., Wang, S. (2019). Fog computing and convolutional neural network enabled prognosis for machining process optimization. Journal of Manufacturing Systems, 52, pp. 32-42. DOI: 10.1016/j.jmsy.2019.05.003

Lockamy III, A., and K. McCormack. (2004). "Linking SCOR Planning Practices to SC Performance: An Exploratory Study.” International Journal of Operations \& Production Management. 24 (12): 1192-1218

Longo, F., Nicoletti, L., Padovano, A., d'Atri, G., Forte, M. (2019). Blockchain-enabled supply chain: An experimental study. Computers and Industrial Engineering, 136, pp. 57-69. DOI: 10.1016/j.cie.2019.07.026

Lu, Y., Xie, R., Liang, S.Y. (2019). Bearing fault diagnosis with nonlinear adaptive dictionary learning. International Journal of Advanced Manufacturing Technology. DOI: 10.1007/s00170-019-03455-1

Mashelkar, R. A. (2018). Exponential Technology, Industry 4.0 and Future of Jobs in India. Review of Market Integration, 10(2), 138-157.

Mathur, A., Dangayach, G. S., Mittal, M. L., \& Sharma, M. K. (2011). Performance measurement in automated manufacturing. Measuring Business Excellence, 15(1), 77-91. https://doi.org/10.1108/13683041111113268

Mathur, S. (2019), The digital enterprise - Thinking Indian industry further. Available at: https://www.businesstoday.in/opinion/columns/digital-enterprise-indian-industrydigitalisation/story/345714.html

Meng, K., Qian, X., Lou, P., Zhang, J. (2018). Smart recovery decision-making of used industrial equipment for sustainable manufacturing: belt lifter case study. Journal of Intelligent Manufacturing. DOI: 10.1007/s10845-018-14392

Ministry of SMMES, 2019, Available here: https://SMMEs.gov.in/know-about-SMMEs

Miragliotta, G., Sianesi, A., Convertini, E., \& Distante, R. (2018). Data driven management in Industry 4.0: a method to measure Data Productivity. IFAC-PapersOnLine, 51(11), 19-24.

Mittal, K. K., \& Jain, P. K. (2014). An overview of performance measures in reconfigurable manufacturing system. Procedia Engineering, 69, 1125-1129. https://doi.org/10.1016/i.proeng.2014.03.100

Mourtzis, D., Vlachou, E. (2018). A cloud-based cyber-physical system for adaptive shop-floor scheduling and condition-based maintenance. Journal of Manufacturing Systems, 47, pp. 179-198.

Muhuri, P. K., Shukla, A. K., \& Abraham, A. (2019). Industry 4.0: A bibliometric analysis and detailed overview. Engineering Applications of Artificial Intelligence, 78(December 2018), 218-235. https://doi.org/10.1016/j.engappai.2018.11.007

Müller, C., Grunewald, M., Spengler, T.S. (2018). Redundant configuration of robotic assembly lines with stochastic failures. International Journal of Production Research, 56 (10), pp. 3662-3682.

NASSCOM, 2018, "Digitalization: the next "big thing" for India's SMEs", Available at: https://www.ey.com/in/en/services/advisory/ey-digitalization-the-next-big-thing-for-indias-smes

Neely, A., M. Gregory, and K. Platts. (1995). "Performance Measurement System Design: A Literature Review and Research Agenda." International Journal of Operations \& Production Management. 15 (4): 80-116.

Ndubisi, N.O., Zhai, X., Lai, K.H., 2020. Small and medium manufacturing enterprises and Asia's sustainable economic development. International Journal of Production Economics. Forthcoming.

Ndubisi, N.O. 2008. Small and medium enterprises in the Pacific Rim. Arah Publications, Malaysia.

O'Donovan, P., Gallagher, C., Leahy, K., O'Sullivan, D.T.J. (2019). A comparison of fog and cloud computing cyberphysical interfaces for Industry 4.0 real-time embedded machine learning engineering applications. Computers in Industry, 110, pp. 12-35. DOI: 10.1016/j.compind.2019.04.016

Oh, J., \& Jeong, B. (2019). Tactical supply planning in smart manufacturing supply chain. Robotics and Computer-Integrated Manufacturing, 55(April 2017), 217-233. https://doi.org/10.1016/j.rcim.2018.04.003 
Kamble, S. S., Gunasekaran, A., Ghadge, A. and Raut, R. (2020), “A performance measurement system for industry 4.0 enabled smart manufacturing system in SMMEs- A review and empirical investigation", International Journal of Production Economics, 229, 107853.

Parasuraman, A., Zeithaml, V. A., \& Berry, L. L. (1985). A Conceptual Model of Service Quality and Its Implications for Future Research. Journal of Marketing, 49(4), 41. https://doi.org/10.2307/1251430

Peruzzini, M., Grandi, F., Pellicciari, M. (2019). Exploring the potential of Operator 4.0 interface and monitoring Computers and Industrial Engineering. DOI: 10.1016/j.cie.2018.12.047

Peter, J. P., Olson, J., Ray, M. L., Ryan, M. J., Sawyer, A. G., \& Silk, A. J. (1982). Measurement Abstracts. Journal of Marketing Research, 19(1), 152-155. https://doi.org/10.1177/002224378201900115

Petrillo, A., De Felice, F., \& Zomparelli, F. (2019). Performance measurement for world-class manufacturing: a model for the Italian automotive industry. Total Quality Management and Business Excellence, 30(7-8), $908-935$. https://doi.org/10.1080/14783363.2017.1408402

Pinzone, M., Albè, F., Orlandelli, D., Barletta, I., Berlin, C., Johansson, B., Taisch, M. (2019). A framework for operative and social sustainability functionalities in Human-Centric Cyber-Physical Production Systems. Computers and Industrial Engineering. DOI: 10.1016/j.cie.2018.03.028

Pistolesi, F., Lazzerini, B., Mura, M.D., Dini, G. (2018). EMOGA: A Hybrid Genetic Algorithm with Extremal Optimization Core for Multiobjective Disassembly Line Balancing. IEEE Transactions on Industrial Informatics, 14 (3), pp. 1089-1098.

Qian, X., Tu, J., \& Lou, P. (2019). A general architecture of a 3D visualization system for shop floor management. Journal of Intelligent Manufacturing, 30(4), 1531-1545.

Qu, Y. J., Ming, X. G., Liu, Z. W., Zhang, X. Y., \& Hou, Z. T. (2019). Smart manufacturing systems: state of the art and future trends. International Journal of Advanced Manufacturing Technology. https://doi.org/10.1007/s00170-019$\underline{03754-7}$

Raileanu, S., Anton, F., Iatan, A., Borangiu, T., Anton, S., Morariu, O. (2017). Resource scheduling based on energy consumption for sustainable manufacturing. Journal of Intelligent Manufacturing, 28 (7), pp. 1519-1530.

Rajput, S., Singh, S.P. (2019). Industry 4.0 - challenges to implement circular economy. Benchmarking. DOI: 10.1108/BIJ-12-2018-0430

Renna, P. (2019). Evaluation of redundant configurations and backup stations to support fault tolerant flow line design. International Journal of Advanced Manufacturing Technology, 101 (1-4), pp. 825-837.

Rivera Torres, P.J., Serrano Mercado, E.I., Llanes Santiago, O., Anido Rifón, L. (2018). Modeling preventive maintenance of manufacturing processes with probabilistic Boolean networks with interventions. Journal of Intelligent Manufacturing, 29 (8), pp. 1941-1952.)

Roldán, J.J., Crespo, E., Martín-Barrio, A., Peña-Tapia, E., Barrientos, A. (2019). A training system for Industry 4.0 operators in complex assemblies based on virtual reality and process mining. Robotics and Computer-Integrated Manufacturing, 59, pp. 305-316. DOI: 10.1016/j.rcim.2019.05.004

Rossit, D.A., Tohmé, F., Frutos, M. A data-driven scheduling approach to smart manufacturing (2019) Journal of Industrial Information Integration. DOI: 10.1016/j.ji1.2019.04.003

Roy, U., Li, Y., \& Zhu, B. (2015). Building a rigorous foundation for performance assurance assessment techniques for "smart" manufacturing systems. Proceedings - 2014 IEEE International Conference on Big Data, IEEE Big Data 2014, 1015-1023. https://doi.org/10.1109/BigData.2014.7004335

Saif, U., Guan, Z., Wang, C., He, C., Yue, L., Mirza, J. (2019). Drum buffer rope-based heuristic for multi-level rolling horizon planning in mixed model production. International Journal of Production Research, 57 (12), pp. 3864-3891. DOI: 10.1080/00207543.2019.1569272

Santos, J., Muñoz-Villamizar, A., Ormazábal, M., \& Viles, E. (2019). Using problem-oriented monitoring to simultaneously improve productivity and environmental performance in manufacturing companies. International Journal of Computer Integrated Manufacturing, 32(2), 183-193. https://doi.org/10.1080/0951192X.2018.1552796

Sari, A., \& Yulia, Y. C. (2019). The Effect of the Processing Time's Variance to the Performance of Sequencing Rule. IOP Conference Series: Materials Science and Engineering, 528(1). https://doi.org/10.1088/1757-899X/528/1/012053

Shepherd, C., and H. Günter. (2006). "Measuring SC Performance: Current Research and Future Directions." International Journal of Productivity and Performance Management. 55 (3): 242-258.

Shin, W. S., Dahlgaard, J. J., Dahlgaard-Park, S. M., \& Kim, M. G. (2018). A Quality Scorecard for the era of Industry 4.0. Total Quality Management \& Business Excellence, 29(9-10), 959-976.

Smeventure, (2017). Available at: https://www.moneycontrol.com/news/business/startup/industries-40-roadmapfor-smes-989555.html

Stefanovic, N. (2015). "Collaborative Predictive Business Intelligence Model for Spare Parts Inventory Replenishment.” Computer Science and Information Systems 12 (3): 911-930.

Stoyanov, S., Ahsan, M., Bailey, C., Wotherspoon, T., Hunt, C. (2019). Predictive analytics methodology for smart qualification testing of electronic components. Journal of Intelligent Manufacturing, 30 (3), pp. 1497-1514.

Tao, F., Tang, Y., Zou, X., Qi, Q. (2019). A field programmable gate array implemented fibre channel switch for big data communication towards smart manufacturing. Robotics and Computer-Integrated Manufacturing, 57, pp. 166-181. DOI: 10.1016/j.rcim.2018.12.005 
Kamble, S. S., Gunasekaran, A., Ghadge, A. and Raut, R. (2020), “A performance measurement system for industry 4.0 enabled smart manufacturing system in SMMEs- A review and empirical investigation", International Journal of Production Economics, 229, 107853.

Tortorella, G.L., Cawley Vergara, A.M., Garza-Reyes, J.A., Sawhney, R. (2020). Organizational learning paths based upon industry 4.0 adoption: An empirical study with Brazilian manufacturers. International Journal of Production Economics, 219, pp. 284-294. DOI: 10.1016/j.ijpe.2019.06.023

Tufano, A., Accorsi, R., Garbellini, F., Manzini, R. (2018). Plant design and control in food service industry. A multidisciplinary decision-support system. Computers in Industry, 103, pp. 72-85.

Uva, A.E., Gattullo, M., Manghisi, V.M., Spagnulo, D., Cascella, G.L., Fiorentino, M. (2018). Evaluating the effectiveness of spatial augmented reality in smart manufacturing: a solution for manual working stations. International Journal of Advanced Manufacturing Technology, 94 (1-4), pp. 509-521.

Venkatraman, N., and J. H. Grant. (1986). Construct Measurement in Organizational Strategy Research: A Critique and Proposal. Academy of Management Review 11 (1): 71-87.

Vogl, G.W., Weiss, B.A., Helu, M. (2019). A review of diagnostic and prognostic capabilities and best practices for manufacturing. Journal of Intelligent Manufacturing, 30 (1), pp. 79-95. DOI: 10.1007/s10845-016-1228-8

Wang, J., \& Li, D. (2019). Task scheduling based on a hybrid heuristic algorithm for smart production line with fog computing. Sensors (Switzerland), 19(5). https://doi.org/10.3390/s19051023

Wang, J., Wang, K., Wang, Y., Huang, Z., Xue, R. (2019a) Deep Boltzmann machine-based condition prediction for smart manufacturing. Journal of Ambient Intelligence and Humanized Computing, 10 (3), pp. 851-861.

Wang, L., \& Nee, A. Y. C. (2009). Collaborative design and planning for digital manufacturing. Collaborative Design and Planning for Digital Manufacturing, 1-413. https://doi.org/10.1007/978-1-84882-287-0

Wang, Y., Zhang, Y., Tao, F., Chen, T., Cheng, Y., Yang, S. (2019b). Logistics-aware manufacturing service collaboration optimisation towards industrial internet platform. International Journal of Production Research, 57 (12), pp. 4007-4026. DOI: 10.1080/00207543.2018.1543967

Wei, H., Li, S., Jiang, H., Hu, J., Hu, J. (2018). Hybrid genetic simulated annealing algorithm for improved flow shop scheduling with makespan criterion. Applied Sciences (Switzerland), 8 (12), art. no. 2621.

Wu, D., Liu, S., Zhang, L., Terpenny, J., Gao, R.X., Kurfess, T., Guzzo, J.A. (2017). A fog computing-based framework for process monitoring and prognosis in cyber-manufacturing. Journal of Manufacturing Systems, 43, pp. 25-34. DOI: $10.1016 /$ j.jmsy.2017.02.011

Yang, M., Zhang, L., \& Denno, P. (2018). Transients of Synchronous Serial Production Lines with Non-Exponential Reliability Machines. IEEE International Conference on Automation Science and Engineering, 2018-August, 1507-1512. https://doi.org/10.1109/COASE.2018.8560592

Zhang, J., Wang, P., Yan, R., \& Gao, R. X. (2018). Long short-term memory for machine remaining life prediction. Journal of manufacturing systems, 48, 78-86.

Zhang, Z., Wang, X., Wang, X., Cui, F., Cheng, H. (2019). A simulation-based approach for plant layout design and production planning. Journal of Ambient Intelligence and Humanized Computing, 10 (3), pp. 1217-1230.

Zhao, G., Liu, S., Lopez, C., Lu, H., Elgueta, S., Chen, H., Boshkoska, B.M. (2019). Blockchain technology in agrifood value chain management: A synthesis of applications, challenges and future research directions. Computers in Industry, 109, pp. 83-99. DOI: 10.1016/j.compind.2019.04.002

Zheng, P., Sang, Z., Zhong, R. Y., Liu, Y., Liu, C., Mubarok, K.,...\& Xu, X. (2018). Smart manufacturing systems for Industry 4.0: Conceptual framework, scenarios, and future perspectives. Frontiers of Mechanical Engineering, 13(2), $137-150$. 
Kamble, S. S., Gunasekaran, A., Ghadge, A. and Raut, R. (2020), “A performance measurement system for industry 4.0 enabled smart manufacturing system in SMMEs- A review and empirical investigation", International Journal of Production Economics, 229, 107853.

\section{Appendix A: List of Journals}

\begin{tabular}{|l|c|}
\hline Journal Name & No. of Articles \\
\hline International Journal of Advanced Manufacturing Technology & 12 \\
\hline International Journal of Production Research & 10 \\
\hline Computers and Industrial Engineering & 8 \\
\hline Journal of Intelligent Manufacturing & 6 \\
\hline IEEE Access & 6 \\
\hline Robotics and Computers Integrated Manufacturing & 5 \\
\hline Journal of Manufacturing Systems & 5 \\
\hline IEEE Transactions on Information Informatics & 5 \\
\hline Computers in Industry & 5 \\
\hline Journal of Ambient Intelligence and Humanized Computing & 4 \\
\hline Computers in Chemical Engineering & 4 \\
\hline International Journal of Production Economics & 3 \\
\hline TQM and Business Excellence & 2 \\
\hline Procedia Manufacturing & 2 \\
\hline International Journal of Computers Integrated Manufacturing & 2 \\
\hline Future Generation Computers System & 2 \\
\hline Engineering Applications of Artificial Intelligence & 2 \\
\hline Benchmarking: An International Journal & 2 \\
\hline Sensors & 1 \\
\hline Procedia Engineering & 1 \\
\hline Mm Science Journal & 1 \\
\hline Measuring Business Excellence & 1 \\
\hline Journal of Quality in Maintenance Engineering & 1 \\
\hline Journal of Industrial Information Integration & 1 \\
\hline IEEE Sensors & 1 \\
\hline Concurrent Engineering Research and Applications & 1 \\
\hline Collaboration Design and Planning for Digital Manufacturing & 1 \\
\hline Applied Soft Computing Journal & 1 \\
\hline Applied Sciences & 1 \\
\hline Annual Reviews in Control & 1 \\
\hline Advances in Engineering Software & 1 \\
\hline Total & 1 \\
\hline
\end{tabular}

